\title{
Physical mixing effects on iron biogeochemical cycling: FeCycle experiment
}

\author{
P. L. Croot, ${ }^{1}$ R. D. Frew, ${ }^{2}$ S. Sander, ${ }^{2}$ K. A. Hunter, ${ }^{2}$ M. J. Ellwood, ${ }^{3}$ S. E. Pickmere, ${ }^{3}$ \\ E. R. Abraham, ${ }^{4}$ C. S. Law, ${ }^{4}$ M. J. Smith, ${ }^{4}$ and P. W. Boyd ${ }^{5}$ \\ Received 6 June 2006; revised 2 March 2007; accepted 20 March 2007; published 20 June 2007.
}

[1] The effects of physical processes on the distribution, speciation, and sources/sinks for Fe in a high-nutrient low-chlorophyll (HNLC) region were assessed during FeCycle, a mesoscale $\mathrm{SF}_{6}$ tracer release during February 2003 (austral summer) to the SE of New Zealand. Physical mixing processes were prevalent during FeCycle with rapid patch growth (strain rate $\left.\gamma=0.17-0.20 \mathrm{~d}^{-1}\right)$ from a circular shape $\left(50 \mathrm{~km}^{2}\right)$ into a long filament of $\sim 400 \mathrm{~km}^{2}$ by day 10 . Slippage between layers saw the patch-head overlying noninfused waters while the tail was capped by adjacent surface waters resulting in a $\mathrm{SF}_{6}$ maximum at depth. As the patch developed it entrained adjacent waters containing higher chlorophyll concentrations, but similar dissolved iron (DFe) levels, than the initial infused patch. DFe was low $\sim 60$ pmol L ${ }^{-1}$ in surface waters during FeCycle and was dominated by organic complexation. Nighttime measurements of $\mathrm{Fe}$ (II) $\sim 20 \mathrm{pmol} \mathrm{L}^{-1}$ suggest the presence of Fe(II) organic complexes in the absence of an identifiable fast $\mathrm{Fe}(\mathrm{III})$ reduction process. Combining residence times and phytoplankton uptake fluxes for DFe it is cycled through the biota 140-280 times before leaving the winter mixed layer (WML). This strong Fe demand throughout the euphotic zone coupled with the low Fe: $\mathrm{NO}_{3}^{-}(11.9 \mu \mathrm{mol}: \mathrm{mol})$ below the ferricline suggests that vertical diffusion of $\mathrm{Fe}$ is insufficient to relieve chronic iron limitation, indicating the importance of atmospheric inputs of $\mathrm{Fe}$ to this region.

Citation: Croot, P. L., R. D. Frew, S. Sander, K. A. Hunter, M. J. Ellwood, S. E. Pickmere, E. R. Abraham, C. S. Law, M. J. Smith, and P. W. Boyd (2007), Physical mixing effects on iron biogeochemical cycling: FeCycle experiment, J. Geophys. Res., 112, C06015, doi:10.1029/2006JC003748.

\section{Introduction}

[2] Iron (Fe) plays a key role in controlling ocean productivity as a limiting factor for phytoplankton growth in large parts of the global ocean [Boyd, 2004]. The low concentrations of $\mathrm{DFe}$ found in surface seawater [Johnson et al., 1997a] are a product of the low solubility [Liu and Millero, 2002] of the thermodynamically favored redox state, $\mathrm{Fe}(\mathrm{III})$, which rapidly forms, or is scavenged by, colloidal and particulate phases. The dissolved forms of $\mathrm{Fe}$ are dominated by complexation with organic ligands [Rue and Bruland, 1995]. Redox changes in Fe speciation also occur through reduction of $\mathrm{Fe}(\mathrm{III})$ organic complexes

\footnotetext{
${ }^{1}$ Leibniz-Institut für Meereswissenschaften (IfM-Geomar), Kiel, Germany. ${ }^{2}$ Department of Chemistry, University of Otago, Dunedin, New Zealand

${ }^{3}$ National Institute of Water and Atmosphere, Hillcrest, Hamilton, New Zealand.

${ }^{4}$ National Institute of Water and Atmosphere, Greta Point, Wellington, New Zealand.

${ }^{5}$ National Institute of Water and Atmosphere Centre for Chemical and Physical Oceanography, Department of Chemistry, University of Otago, Dunedin, New Zealand.
}

Copyright 2007 by the American Geophysical Union. 0148-0227/07/2006JC003748\$09.00
[Barbeau et al., 2001; Powell and Wilson-Finelli, 2003] and colloidal iron [Johnson et al., 1994] by photochemical mechanisms and by extracellular processes [Maldonado and Price, 2001] to $\mathrm{Fe}(\mathrm{II})$; which may exist on timescales of minutes to hours [Croot and Laan, 2002; Croot et al., 2001]. The combined effects of organic complexation and redox cycling can greatly increase iron bioavailability to phytoplankton [Anderson and Morel, 1980]. Thus for any study investigating iron controls on primary productivity in the open ocean it is of great importance to determine the sources, sinks, fluxes and cycling of Fe species.

[3] Understanding mixing processes in the surface ocean is also key to unraveling the biogeochemical cycling of bioimportant elements such as Fe. Vertical mixing occurs over different spatial and timescales [Denman and Gargett, 1983] and can strongly influence the supply of resources to phytoplankton [MacIntyre, 1998], such as nutrients and light. The dynamical nature of the surface ocean has led to two concepts of mixed layers [Brainerd and Gregg, 1995]: (1) The Active Mixing Layer (AML) is defined as the depth zone which is actively mixed from the surface at a given time and generally corresponds to a zone where strong surface forcing induces turbulent mixing. (2) The Mixed Layer Depth (MLD) is the maximum depth reached by the AML on timescales of 24 hours or more. In the present 
work we use estimates of AML and MLD and mixing rates (based on work by Cisewski et al. [2005]) to examine the spatial and temporal scales for mixing during FeCycle and its effects on Fe biogeochemistry.

[4] FeCycle [Boyd et al., 2005] was located in the South West Pacific, in offshore waters eastward of the South Island of New Zealand. In brief the surface water masses in this region comprise two main types [Banse and English, 1997; Boyd et al., 1999]; the cold, less saline high-nutrient low-chlorophyll (HNLC) sub-Antarctic (SA) to the south and warm, salty, low-nutrient subtropical (ST) waters to the north. The two water masses are separated by the subtropical front $(\mathrm{STF})$, which in this region is bathymetrically trapped both close to the continental shelf of the Southern South Island, where it is known as the Southland Current [Heath, 1972], and along the Chatham Rise [Sutton, 2001], resulting in minimal seasonal movement of the front in contrast to observations of the STF and other circumpolar fronts in the open ocean [Orsi et al., 1995].

[5] In the present work we examined the effect of physical mechanisms on the vertical distribution, speciation, inventory and potential sources of $\mathrm{Fe}$ in near surface seawater during the FeCycle experiment, a $\mathrm{SF}_{6}$ tracer release study of ambient Fe cycling in the South Western Pacific Ocean.

\section{Methods}

\subsection{Experimental Design}

[6] FeCycle was performed (R.V. Tangaroa) from 29 January to 13 February 2003. Prior to the voyage a suitable site was identified, on the basis of previous work in this region, at $178^{\circ} 30^{\prime} \mathrm{E}, 46^{\circ} 30^{\prime} \mathrm{S}$. This site combined the necessary prerequisites for a mesoscale tracer release for the purposes of FeCycle; stable physical conditions (little chance of subduction, mixed layer 30-50 m) and HNLC characteristics [Boyd et al., 2005]. The suitability of the selected site was then examined during a preinfusion survey which commenced on 30 January until 1 February, comprising of XBT release's interspersed with CTD casts to $1 \mathrm{~km}$ depth, and underway biogeochemical sampling using a nontoxic pumped seawater supply from $5 \mathrm{~m}$ depth [Boyd and Abraham, 2001], for temperature (T), salinity (S) (Seabird thermosalinograph), chlorophyll (Turner fluorometer), $\mathrm{F}_{\mathrm{v}} / \mathrm{F}_{\mathrm{m}}$ (Chelsea Instruments Fast Repetition rate Fluorometer [after Boyd and Abraham, 2001]), dissolved nutrients [after Frew et al., 2001] and dissolved Fe (clean tow-fish at $4 \mathrm{~m}$ depth [after Bowie et al., 2001]). An appropriate site was located at $178.72^{\circ} \mathrm{E}, 46.24^{\circ} \mathrm{S}$ on 1 February 2003, with the $\mathrm{SF}_{6}$ release commencing at 0200 hours (local time) on 2 February 2003 (see below).

[7] During the 10-day duration of FeCycle we performed several dedicated sets of measurements at the centre of the patch (defined as the highest $\mathrm{SF}_{6}$ concentrations [Law et al., 1998]). These included budget sampling (on 4 days), depthresolved sampling (2 days) and diel sampling (2 days). Each sampling period was interspersed with overnight mapping of the areal extent of the patch (10-14 hours duration) and concurrent sampling of lateral gradients in physical, chemical and biological properties. A summary of the station activity during FeCycle is found in the auxiliary material $^{1}$.

\subsection{1. $\mathrm{SF}_{6}$ Tracer Addition}

[8] The tracer $\mathrm{SF}_{6}$ was injected into the surface mixed layer using procedures described previously [Law et al., 1998]. The $\mathrm{SF}_{6}$ was released at a depth of $7 \mathrm{~m}$ by means of a surface drogue and the release track was over an area of $\sim 49 \mathrm{~km}^{2}$ (i.e., a $7 \mathrm{~km} \times 7 \mathrm{~km}$ square) which was completed in 12 hours. There was no addition of Fe with the $\mathrm{SF}_{6}$. At the completion of the tracer release, an underway mapping survey was undertaken to determine the surface extent of the $\mathrm{SF}_{6}$ labeled waters. The start of the experiment was taken as 1200 hours (local time NZST) on 2 February 2003 (00:00 2 February 2003 UTC). For the sampling regime (outlined above) followed in FeCycle, day 1 was nominally defined as 3 February 2003, and the final day of the experiment was 12 February (day 10).

\subsubsection{Hydrographic Sampling}

[9] Water for all components of the mixed layer budget on station was obtained using a clean epoxy-coated sampling fish, trace-metal clean Teflon tubing and Teflon pump [after Bowie et al., 2001] with a plastic RBR (Richard Brancker Research, XR-420) temperature and pressure logger attached near the water intake. The depth of the inlet could be varied by letting out more hose until a maximum of $\sim 80 \mathrm{~m}$ depth was achieved. Flow rates were maintained at $1-2 \mathrm{~L} \min ^{-1}$ throughout the sampling period at each discrete depth and before each sample was taken the line was flushed for several minutes ( $2-3$ hold-up volumes) to ensure the sample water corresponded to the sampling depth. The line was back flushed with acid after each deployment prior to stowing. In this manner clean seawater was directly available in the laboratory in a HEPA filtered air environment with minimization of sample processing times. Typically samples for a budget station could be acquired in less than 3 hours. During FeCycle samples for DFe were collected directly from the sample line after filtration through $0.2 \mu \mathrm{m}$ filters: (1) FIA-chemiluminescence (Sartorius-Sartobran 300) and (2) GFAA extraction (Pall Supor AcroPak 200). Unfiltered samples were taken directly from the sampling line without filtration. During $\mathrm{SF}_{6}$ mapping periods, surface seawater was collected using the same 'fish' system deployed from a boom arm 3-4 m away from the ship's starboard side (temperature and pressure logger removed).

[10] Seawater samples at depths below the extent of the 'fish' system (i.e., >80 m) were obtained using modified Teflon coated PVC General Oceanics (Miami, FL, USA) GoFlo $(8 \mathrm{~L})$ bottles on a trace metal clean Superbraid hydrowire using established protocols [Bruland et al., 1979]. Filtered samples were collected using slight $\mathrm{N}_{2}$ overpressure and filtered using $0.2 \mu \mathrm{m}$ filters as noted for the underway measurements for GFAA; for the GO-FLO samples the same filtration setup was used by both analytical techniques.

\subsection{Analytical Methods for Iron}

[11] Analytical work was performed in a container fitted out with class 100 laminar flow hoods all enclosed in a

${ }^{1}$ Auxiliary materials are available at ftp://ftp.agu.org/apend/jc/ $2006 j \mathrm{jc} 003748$. 
room constructed with a frame of plastic piping and covered in plastic sheeting to prevent contamination. All sampling, filtration and sample manipulations were performed using trace-metal clean techniques under HEPA filtered air. All plasticware used was precleaned by acid-washing techniques and stored in acid cleaned bags prior to use. Subboiled acids [Kuehnen et al., 1972], prepared in either Quartz or Teflon subboiling stills were used exclusively for sample analysis (denoted hereafter by the prefix Q (Quartz-distilled) or $\mathrm{T}$ (Teflon distilled)).

[12] For the FeCycle experiment DFe was measured by two independent methods: (1) Onboard analysis with flow injection analysis (FIA) using Chemiluminscence for $\mathrm{Fe}$ (II) after preconcentration on 8-Hydroxyquinoline-TSK column. (2) Laboratory-based graphite furnace atomic absorption analysis (GFAA) with preconcentration by solvent extraction of seawater samples.

2.2.1. Seawater Dissolved Iron Measurements: Flow Injection Analysis for Fe

[13] Samples were analyzed for DFe at sea using an FeLume Chemiluminescence analyzer (Waterville Analytical, Maine) following sulfite reduction of $\mathrm{Fe}$ (III) to $\mathrm{Fe}(\mathrm{II})$ and subsequent analysis by flow injection analysis of the $\mathrm{Fe}$ (II) induced luminol chemiluminescence [Bowie et al., 1998]. Samples were acidified with Q-HCl $(100 \mu \mathrm{L} / 100 \mathrm{~mL}$ sample), allowed to stand for a minimum of 1 hour at which point the sample was buffered to $\mathrm{pH} 5.0$ with $1 \mathrm{~mol} \mathrm{~L}^{-1}$ $\mathrm{NH}_{4} \mathrm{OAc}$ and the reducing agent $\mathrm{Na}_{2} \mathrm{SO}_{3}$ was added (final concentration $40 \mu \mathrm{mol} \mathrm{\textrm {L } ^ { - 1 }}$ ) in order to reduce all the $\mathrm{Fe}$ (III) to $\mathrm{Fe}(\mathrm{II})$. After the reduction was complete, typically 1-2 hours [Bowie et al., 1998], the sample was analyzed by flow injection analysis after preconcentration on 8-hydroxyquinoline resin [Landing et al., 1986]. Daily blanks values (range $40 \pm 20 \mathrm{pM}, \mathrm{n}=9$ ) were ascertained by double addition of acid, buffer and reducing agent to select replicate samples. Typical daily detection limits, defined as $3 \sigma$ of the blank, were $\sim 40$ pM; precisions were typically $5-8 \%$ at the $0.2 \mathrm{nM}$ level. Individual precisions for each sample were estimated from 3 or more replicate analyses of the FIA sample.

\subsubsection{Seawater Dissolved Iron Measurements: Solvent Extraction}

[14] Dissolved Fe was determined postcruise in the laboratory (NIWA-Hamilton) on $\mathrm{T}-\mathrm{HNO}_{3}$ acidified $(\mathrm{pH}<1.8)$ samples using a combination of solvent extraction techniques [Bruland et al., 1979; Danielsson et al., 1978]. Briefly, $120 \mathrm{~g}$ or $250 \mathrm{~g}$ of seawater was buffered to a $\mathrm{pH}$ of 4.5 with purified ammonium acetate buffer in a $250-\mathrm{mL}$ Teflon separation funnel. Purified ammonium pyrrolidinedithiocarbamate (APDC)/sodium diethyldithiocarbamate (DDC) solution was then added followed by $5 \mathrm{~mL}$ of clean chloroform. The sample was then extracted by shaking for $3 \mathrm{~min}$. After allowing the phases to separate, the chloroform was drained and the sample extracted a second time for 2 min with $5 \mathrm{~mL}$ of chloroform. The chloroform extracts were combined and acidified with $75 \mu \mathrm{L}$ of $\mathrm{T}-\mathrm{HNO}_{3}$, shaken and left to react for 1 hour. Metals back-extracted from the chloroform phase were diluted to $1 \mathrm{~mL}$ with Nanopure water, shaken and left overnight before analysis by GFAA using a Perkin-Elmer 4100 ZL with Zeeman background correction. Blanks and recoveries were conducted with each sample batch processed. Reagent blanks were found to be $48 \pm 14 \mathrm{pM}$ ( $\mathrm{n}=3$, 1 sample omitted) for analysis of previously extracted samples (detection limit $=$ $3 \sigma=42 \mathrm{pM})$.

\subsubsection{Iron Speciation in Seawater}

[15] Samples were analyzed for Fe speciation using voltammetry with the competing ligand 2-(2-Thiazolylazo)p-cresol (TAC) [Croot and Johansson, 2000]. Full details of the CLE-ACSV theory for determining DFe speciation can be found elsewhere [Croot and Johansson, 2000; Croot et al., 2004b]. All data were analyzed with a single ligand model using a nonlinear fit to a Langmuir adsorption isotherm with the nonlinear least squares Levenberg-Marquardt algorithm (Formulated as a Labview ${ }^{\mathrm{TM}}$ virtual instrument) to solve the relevant equations (see Croot and Johansson [2000] for details) for $K$ and [L] with $\mathrm{Fe}^{\prime}$ as the independent variable and $[\mathrm{FeL}] /\left[\mathrm{Fe}^{\prime}\right]$ or $[\mathrm{FeL}]$ as the dependent variable. Error estimates for each term were constructed using $\chi^{2}$ and the variance estimates from the fitted solution matrix. Conditional stability constants were calculated using $\beta_{\mathrm{Fe}(\mathrm{TAC}) 2}^{\prime}=$ $10^{12.4} \mathrm{M}^{-2}$ (in Fe ${ }^{\mathrm{III}}$ notation $\beta_{\mathrm{Fe}(\mathrm{TAC}) 2}=10^{22.4} \mathrm{M}^{-2}$ ) and an $\alpha_{\mathrm{Fe}^{\prime}}$ of $10^{10.0}$.

\subsection{4. $\mathrm{Fe}$ (II) Measurements}

[16] $\mathrm{Fe}(\mathrm{II})$ was determined using a chemiluminescence flow injection analysis system [Croot and Laan, 2002]. No preconcentration of $\mathrm{Fe}(\mathrm{II})$ was performed to eliminate possible artifacts from $\mathrm{pH}$ or redox environment changes imposed by a preconcentration step [Croot and Hunter, 2000]. Samples from vertical profiles were maintained at the ambient seawater temperature $\left(\sim 14^{\circ} \mathrm{C}\right)$ to maintain oxidation of $\mathrm{Fe}(\mathrm{II})$ at in situ rates. The detection limit for this technique during this work (all analysis) ranged from 4 to $20 \mathrm{pM}$, and depended mostly on the background chemiluminescence from the luminol reagent. Only values $>3 \sigma$ of the blank above the detection limit are reported here. Concentrations of $\mathrm{Fe}$ (II) for underway samples were based on comparison of peak area (not height) with standard solutions. Peak width and shape was also used as a criteria for the determination of $\mathrm{Fe}$ (II) at $<100 \mathrm{pM}$ levels as at these low levels the presence of a small injection peak can bias peak height based analysis to anomalously higher Fe(II) levels. A further criteria for the detection of Fe(II), which has been employed during $\mathrm{Fe}$ addition experiments (EisenEx, SOFeX and EIFeX [e.g., Croot et al., 2005]), is that discrete samples should be measurable for at least one halflife $\left(t_{1 / 2}\right)$ in order to confirm the signal is from $\mathrm{Fe}$ (II) and not other species. In practice this raises the quantifiable limit above the detection limit based on the blank and that this new limit is dependent on the oxidation time of $\mathrm{Fe}(\mathrm{II})$ in each sample.

\section{3. $\mathrm{SF}_{6}$ Measurements}

[17] Underway $\mathrm{SF}_{6}$ measurements was achieved by an automated sparge-cryogenic trap system coupled to an Electron Capture Detector-Gas Chromatograph (ECD-GC), as previously described by Law et al. [1998]. Surface water was obtained from the ships nontoxic surface supply and analyzed in continuous mode, with a measurement obtained every $3.5 \mathrm{~min}$. Vertical profiles of $\mathrm{SF}_{6}$ were performed on $350 \mathrm{~mL}$ water samples obtained from CTD hydrocasts using a discrete vacuum-sparge cryogenic trap system [Law et al., 1994]. The Tracer Layer Depth (TLD) at each station was defined as the depth at which the $\mathrm{SF}_{6}$ concentration was 

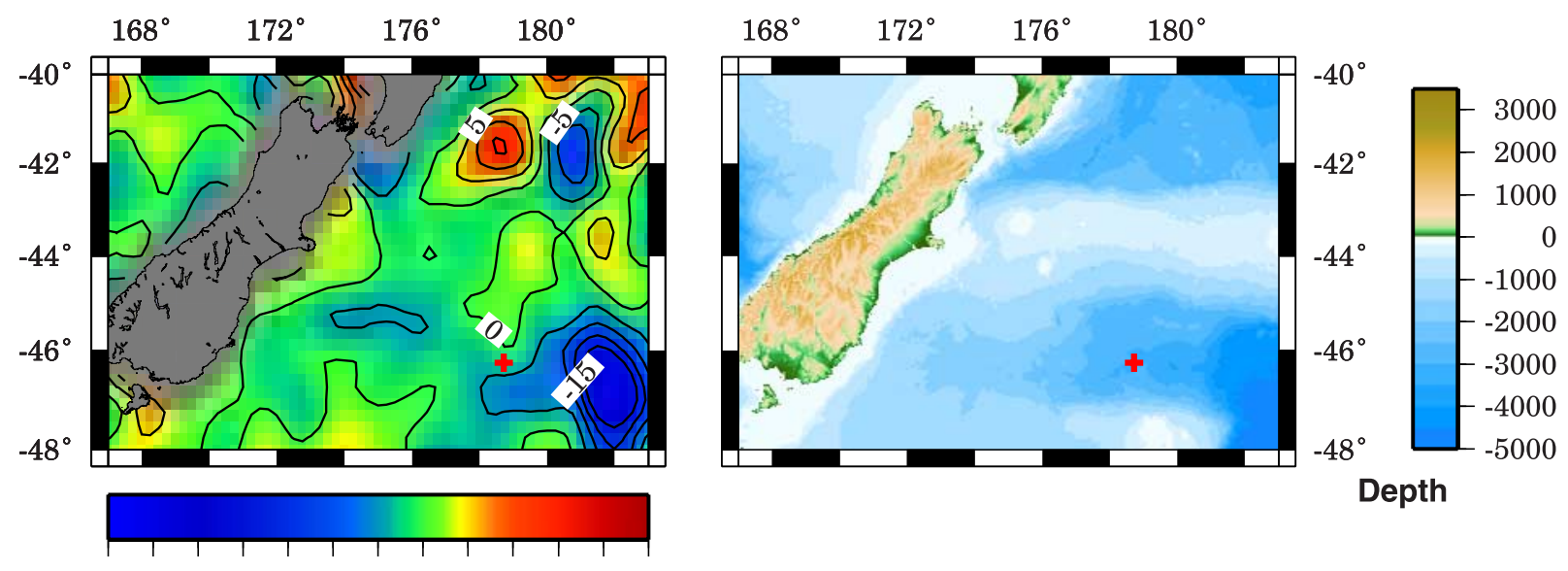

$\begin{array}{llllllll}-35-30-25-20-15-10 & -5 & 0 & 5 & 10 & 15 & 20 & 25\end{array}$

$\mathrm{SSH}$ anomaly $\mathrm{cm}$

Figure 1. (left) Sea surface height anomaly (26 January 2003) prior to the beginning of the FeCycle experiment. (right) Bathymetry and topography map of the study area; the FeCycle patch was initially located at $178.72^{\circ} \mathrm{E} 46.24^{\circ} \mathrm{S}$ (denoted by a red cross in each plot).

reduced to $50 \%$ of the surface mixed layer value (see auxiliary material Table S2).

\subsection{Shipboard Ancillary Measurements}

[18] Meteorological data (wind speed and direction) was collected on 1-min intervals and the data reported in this paper is constructed from 10 min averages of the raw data. Wind stress was calculated according to Price et al. [1986]. Sensible and latent heat fluxes were calculated according to bulk formulae (Häkkinen and Cavalieri [1989] as cited by Cisewski et al. [2005]). Thorpe displacements [Thorpe, 1977] were estimated from CTD data [Galbraith and Kelley, 1996; Johnson and Garrett, 2004] using a similar approach to [Cisewski et al., 2005], this approach was used only to roughly identify and estimate mixing rates in the AML.

[19] Incident PAR (Photosynthetically available radiation) was recorded continuously (10-min averaged) and spectrally resolved data from the $7 \mathrm{SeaWiFS}$ bands (412 to $683 \mathrm{~nm}$ ) were obtaining using the shipboard reference sensor for the Satlantic (Halifax, NS, Canada) SPMR (Spectrally Profiling Multi Radiometer) mounted high on the ships super structure with a clear sky view. Vertical spectrally resolved (305, $320,340,380 \mathrm{~nm}$ ) UV profiles were obtained at local noon (1300 NZST) using a Biospherical Instruments (San Diego, California) PUV (profiling ultra violet radiation sensor) deployed from midships with vessel orientated so that the sun was not shaded from the sensor (ship shadow). Water column transmissivity data were collected using a $25 \mathrm{~cm}$ transmissometer attached to the CTD; beam attenuation coefficients were subsequently calculated from the transmission data $\left(c_{\mathrm{p}}=\log \left(\mathrm{T} / \mathrm{T}_{0}\right) / 0.25\right.$ where $\mathrm{T}$ is the transmission and $\mathrm{T}_{0}$ the transmission in pure water).

\subsection{Satellite Data}

[20] Individual MODIS (AQUA, level 2 LAC) and SeaWiFS swaths (level 2, GAC, browse) were obtained from the Ocean Color website (http://oceancolor.gsfc.nasa.gov/) and the images reprocessed using SeaDAS [Baith et al., 2001]. Daily satellite swaths of the study region were combined into a single composite image for each day. Sea surface temperature (SST) data were also obtained from the MODIS AQUA images using SeaDAS. Aerosol optical absorption at $865 \mathrm{~nm}$ was obtained from individual MODIS (TERRA, level 2 LAC) and SeaWiFS swaths (level 2, GAC, browse) acquired through the GES Distributed Active Archive Centre (http://daac.gsfc.nasa.gov/data/) and the images reprocessed using MATLAB ${ }^{\text {TM }}$. Satellite images were finally displayed as postscript images using the Generic Mapping Tools (GMT) software [Wessel and Smith, 1998].

[21] The air masses encountered during FeCycle were classified according to 4-day back trajectories calculated for arrival heights of 100, 500 and $1000 \mathrm{~m}$ above the ship's position (NOAA Air Resources Laboratory HYSPLIT model, FNL data set). Sea surface height anomaly (SSH) data was kindly provided by the Colorado Center for Astrodynamics Research, University of Colorado, Boulder, and was derived from TOPEX/Poseidon data using a climatological mean acquired during the period 1993-1996.

\section{Results}

\subsection{Initial Physical Setting}

[22] SSH data prior to and during the FeCycle experiment showed the presence of a large depression centered to the east of the study site (Figure 1). This depression was consistent with a cyclonic or clockwise rotating eddy, which occur frequently in this region [Morris et al., 2001; Stanton and Morris, 2004]. The eddy appeared to be stationary and may have been bathymetrically trapped to the eastern edge of the Bounty Plateau and the southern boundary of the Bounty Trough (Figure 1). In this region the dominant surface circulation is believed to be a cyclonic flow around the western Bounty Trough [Heath, 1975; Morris et al., 2001].

[23] Satellite SST (Figure 2) on 4 February 2003 (day 2), show a strong north-south gradient centered at $46^{\circ} 30^{\prime} \mathrm{S}$ with warmer waters $\left(<13^{\circ} \mathrm{C}\right)$ to the north and cooler waters to the south. Surface chlorophyll (MODIS-AQUA) concentrations 

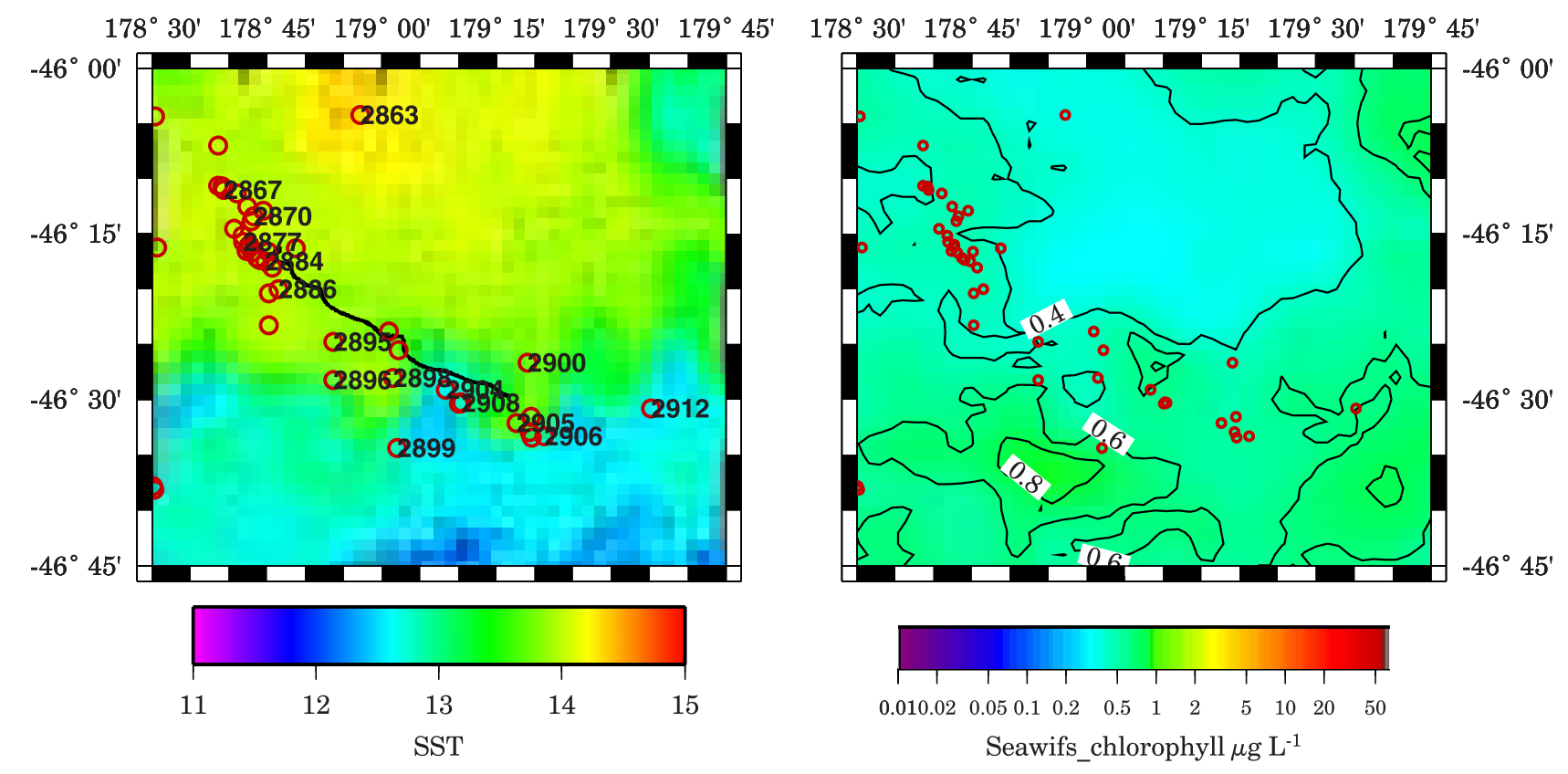

Figure 2. (left) MODIS AQUA (single swath A2003034014500, 4 February 13:45 NZST 2003) image for SST. Red circles indicate the location of CTD stations occupied during the course of FeCycle with the relevant station numbers shown for a few selected stations. The solid black line indicates the passage of the GPS buoy marking the center of the patch. (right) MODIS AQUA (single swath A2003034014500, 4 February 13:45 NZST 2003) image for chlorophyll $a$. Contour lines are shown in black.

at this time ranged from 0.2 to $1 \mu \mathrm{g} \mathrm{L}^{-1}$ (Figure 2) and varied inversely to temperature with highest values associated with cold waters to the South and lowest chlorophyll levels in the core of the warm water to the north. Surface chlorophyll in the survey region had increased during the month of January as evidenced by MODIS-AQUA images (Figure 3) for 8 and 25 January and 2 February (day 0 in FeCycle). Chlorophyll concentrations for the Bounty Trough were slightly higher for this time of year relative to previous years for which data exists; Coastal Zone Colour Scanner (CZCS) data for period 1979-1986 [Banse and English, 1997] in which only occasional blooms were found, while Murphy et al. [2001] found in their analysis of SeaWiFS data from 1998-2000, chlorophyll rarely exceeded $0.4 \mu \mathrm{g} \mathrm{L}^{-1}$ with a weak seasonal cycle (maximum in February/March). A more recent study by Boyd et al. [2004] using 8 day composites of OCTS and SeaWiFS data for the Bounty Trough region found high-chlorophyll $\left(\sim 0.8 \mu \mathrm{g} \mathrm{L}^{-1}\right)$ events of large spatial extent for February/ March in 1997-1999, and in particular 2001, these high values were variable in extent, magnitude and location but appeared to persist on timescales of weeks.

[24] The initial survey of the region prior to the $\mathrm{SF}_{6}$ infusion using XBT and CTD data from a series of transects centered on the position of the NIWA Southern Bio-optical/ traps mooring at $46^{\circ} 38^{\prime} \mathrm{S}, 178^{\circ} 31^{\prime} \mathrm{E}$, reinforced the satellite data. During this survey, warmer and less saline water was found to the north east of the mooring site. Colder more saline water with higher nutrient and chlorophyll levels was observed to the south and west of the mooring. There was only a small salinity range across the entire presurvey area with a gradient running from the southwest, with a salinity minimum of 34.28 , to the northeast and east, where salin- ities were $\sim 34.36$. Slightly deeper MLDs $(\sim 60 \mathrm{~m})$ were observed to the south of the mooring than to the north $(\sim 50 \mathrm{~m})$. Shallow MLD $(\sim 24 \mathrm{~m})$ to the east of the mooring (Station 2858) were caused by warm surface layer from the north overriding cooler surface layer with higher chlorophyll fluorescence from the south, resulting in a distinct chlorophyll maximum below the mixed layer. The conditions at this time were typical of SA surface waters from their salinity and nutrient properties [Boyd et al., 1999] but were warmer than previous observations. This warmer water was probably related to hot weather experienced in January 2003 over the central parts of the Eastern South Island in which temperatures exceeded $30^{\circ} \mathrm{C}$ for several days (NZ Met Service: Learning Centre, www.metservice. co.nz). Large bush fires were occurring in Australia also at this time with reports of smoke haze over New Zealand on 20 January, when a reddish sky color was reported over Northland and Auckland, and on 27 January when "brown rain" was reported in Wellington.

\subsection{Development of the $\mathrm{SF}_{6}$ Patch}

[25] The FeCycle patch was infused with $\mathrm{SF}_{6}$ over a 13 hour period on 2 February 2003 at $46^{\circ} 07^{\prime} \mathrm{S}, 178^{\circ} 38^{\prime} 64 \mathrm{E}$ as a $7 \times 7 \mathrm{~km}$ square. At the completion of the infusion a surface survey was performed and the initial patch surface area was found to be $47 \mathrm{~km}^{2}$. The $\mathrm{SF}_{6}$ was initially infused into surface waters (S 34.33, T 13.89), mixing to $\sim 30 \mathrm{~m}$, $\sigma_{\mathrm{t}}<25.78$, after 24 hours. The patch drifted slowly with strong inertial motions superimposed on the mean path toward the southeast over the first 3 days $\left(\sim 0.19 \mathrm{~m} \mathrm{~s}^{-1}\right.$, 3 -day average based on the drift of the central GPS-buoy) and maintained this heading for the following 3 days $\left(\sim 0.16 \mathrm{~m} \mathrm{~s}^{-1}\right)$. On 9 February the patch started to increase 


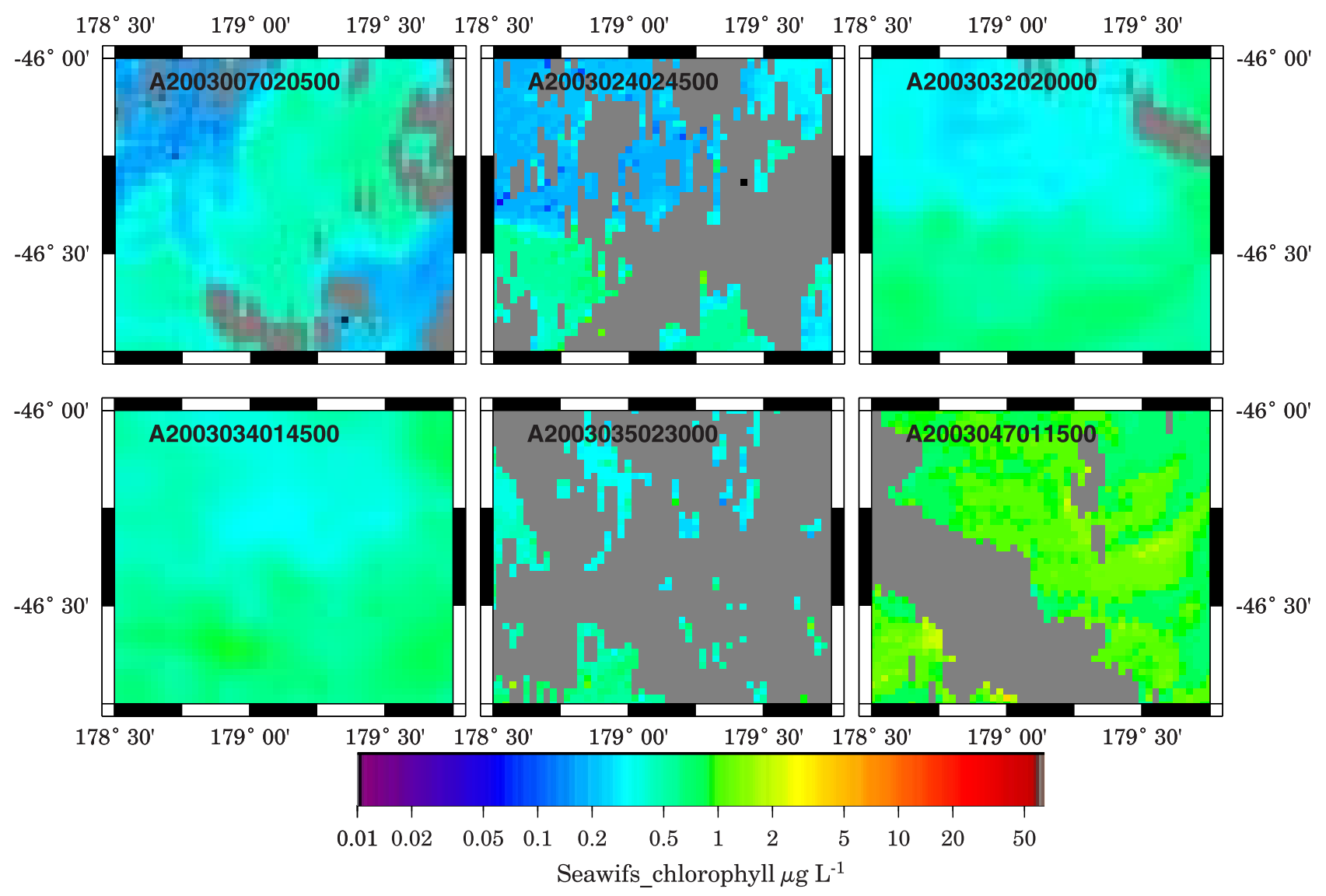

Figure 3. Composite MODIS AQUA images for chlorophyll $a$, before and during FeCycle: (top left) 8 January 2003, (top middle) 25 January 2003, (top right) 2 February 2003, (bottom left) 4 February 2003, (bottom middle) 5 February 2003, and (bottom right) 17 February 2003. All dates/times are in NZST.

in velocity to the southeast (mean velocity $\sim 0.49 \mathrm{~m} \mathrm{~s}^{-1}$ ) and over the last days of $\mathrm{FeCycle} \mathrm{it} \mathrm{accelerated} \mathrm{again} \mathrm{and}$ moved slightly northeast (Figure 2). By the end of FeCycle a final surface survey estimated the patch at $\sim 400 \mathrm{~km}^{2}$. Surface maps of $\mathrm{SF}_{6}$ constructed from daily nocturnal mapping of the patch, corrected for Lagrangian drift by reference to the central GPS buoy, are shown in Figure 4. During FeCycle the patch developed from an initially circular shape to a long filament as is expected for a tracer under pure strain flow [Abraham et al., 2000].

[26] The T/S properties of the $\mathrm{SF}_{6}$ patch changes over the course of FeCycle were small but significant (Figure 5). Surface water temperatures in the $\mathrm{SF}_{6}$ patch warmed significantly from 13.9 to $14.3^{\circ} \mathrm{C}$ owing in part to summer heating. This temperature increase of the $\mathrm{SF}_{6}$ patch was most notably over the last 5 days. Salinity increased within the $\mathrm{SF}_{6}$ patch from 34.33 to 34.35 suggesting that the patch was consistently mixing with higher-salinity out patch waters. On several occasions stations exhibited T/S properties consistent with the development of horizontal mixing between surface layers above the MLD, with the patch both overriding and being capped by $\mathrm{SF}_{6}$ free surface waters. For the majority of $\mathrm{FeCycle}$, mixing was between surface water end-members of slightly different salinities (Figure 5). On the basis of the observations made here it is clear however that temperature was the major controlling factor for density stratification in surface waters during FeCycle.
[27] Estimates of MLDs $\left(\Delta \sigma_{\mathrm{t}}\right.$ of either 0.02 or 0.05 from the upper $5 \mathrm{~m}$ of the water column) showed an initial deepening from $\sim 20 \mathrm{~m}$ to $45 \mathrm{~m}$ in response to increasing wind stress over the first 48 hours of FeCycle (Figure 6). As the experiment continued and the wind stress reduced, mixed layers shallowed to $\sim 20 \mathrm{~m}$. A distinct salinity minimum in the upper water column was present at all stations during this time at $\sim 50 \mathrm{~m}$ and appeared to limit the effects of wind mixing to the depth of this seasonal mixed layer (SML), well above the deeper winter mixed layer (WML) found at $\sim 120 \mathrm{~m}$. The $\sigma_{\mathrm{t}}=25.75$ isopycnal deepened over the first 96 hours in response to the windforcing to $\sim 40 \mathrm{~m}$ then rising again to $30 \mathrm{~m}$ where it remained for some time until sinking again to $40 \mathrm{~m}$ over the last 2 days of FeCycle. Low-density water of $\sigma_{\mathrm{t}}=25.7$ was present initially in only the upper $10 \mathrm{~m}$, and was lost by mixing with denser deeper waters during the period of sustained high winds, returning with relaxation of the wind mixing and gradually deepening as the surface waters warmed.

[28] Chlorophyll levels also increased in both the FeCycle patch [Boyd et al., 2005] and throughout the survey region as seen by MODIS-AQUA (Figure 3). In patch discrete sampling showed a doubling in the chlorophyll content from 0.4 to $0.8 \mu \mathrm{g} \mathrm{L}^{-1}$ of the surface waters during FeCycle [McKay et al., 2005]. This increase continued after FeCycle as Satellite chlorophyll estimates for 17 February show 

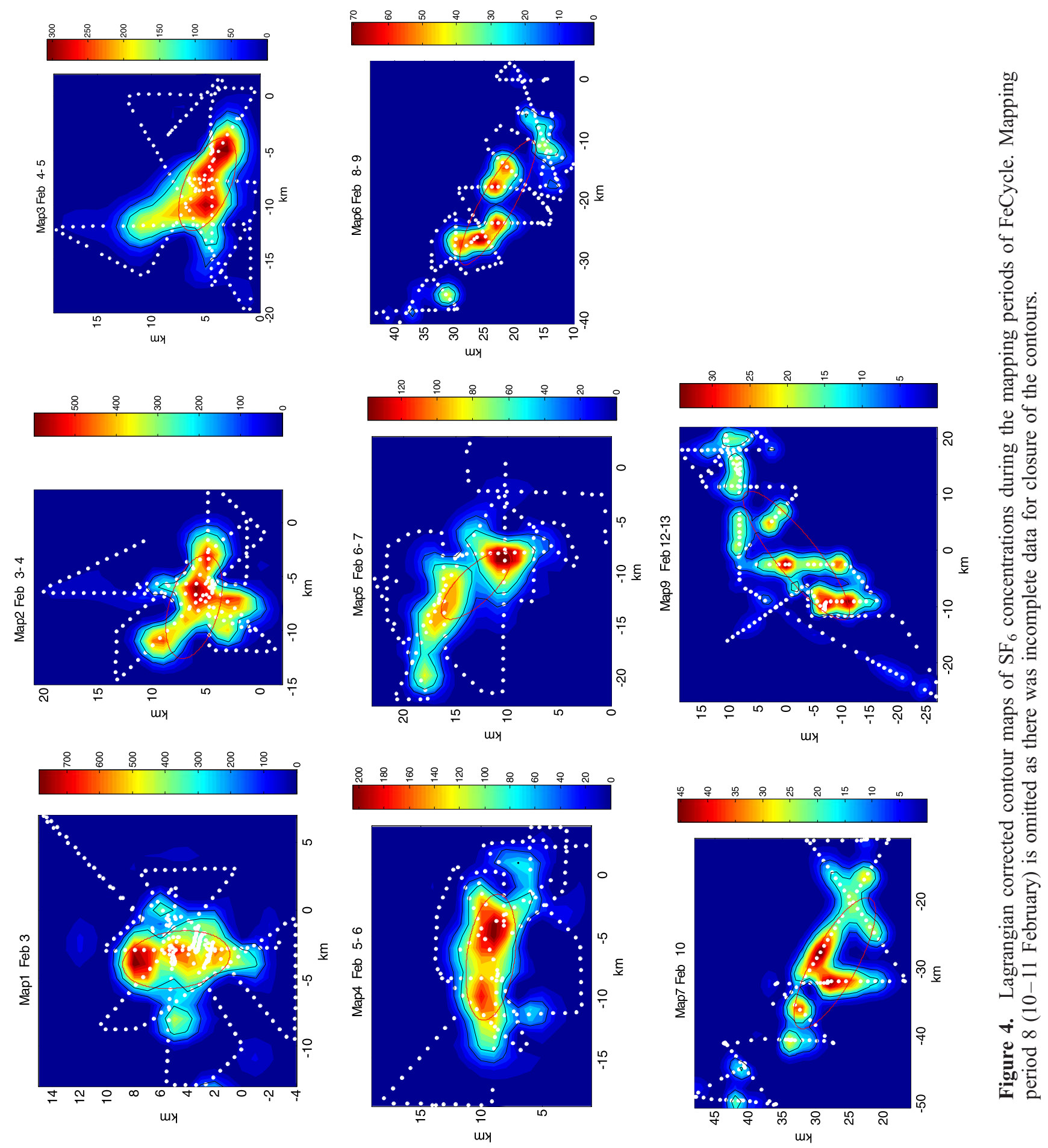


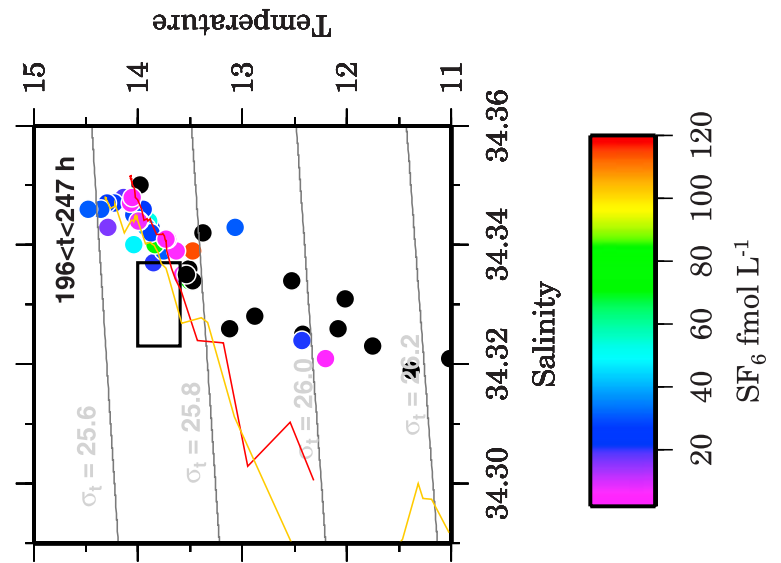

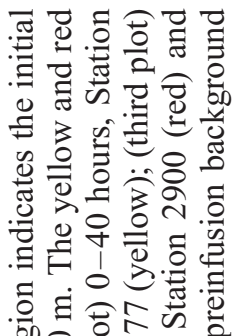

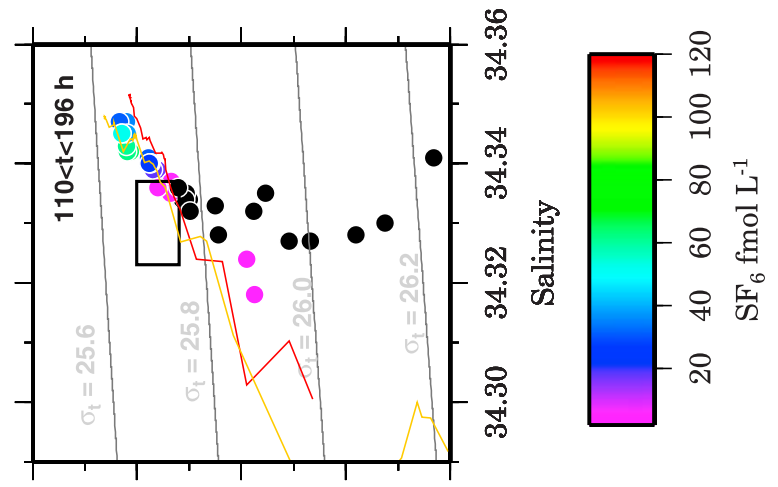

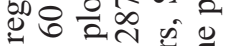

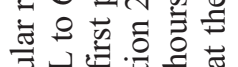

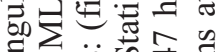

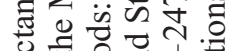

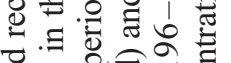

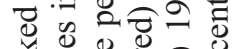

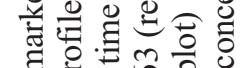
至 0 可 뭉 可割 음

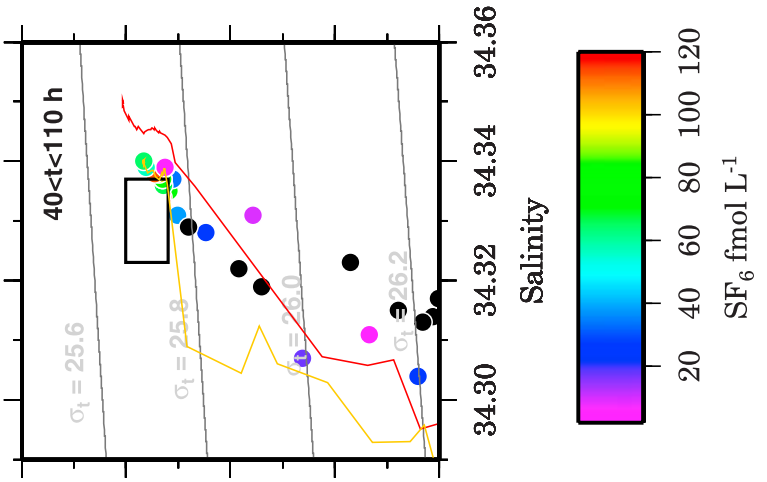

论 I 5 응

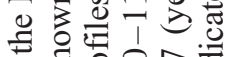

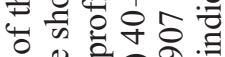
ธี

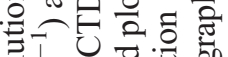
ㄱ. 융

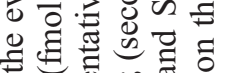

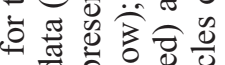

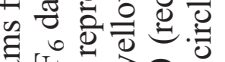
武咭 要 of

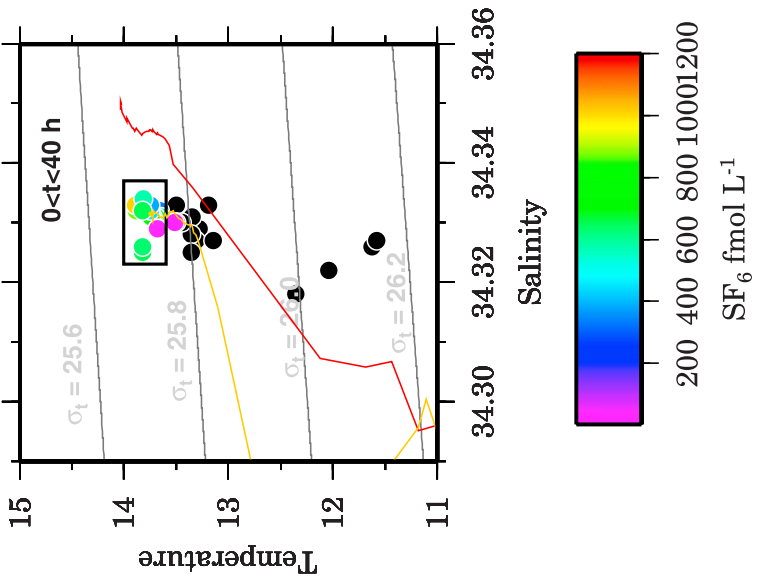

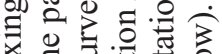

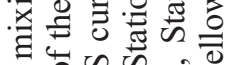

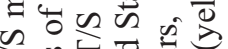

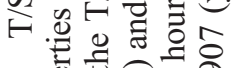
ம

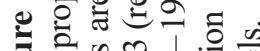

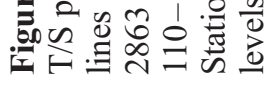



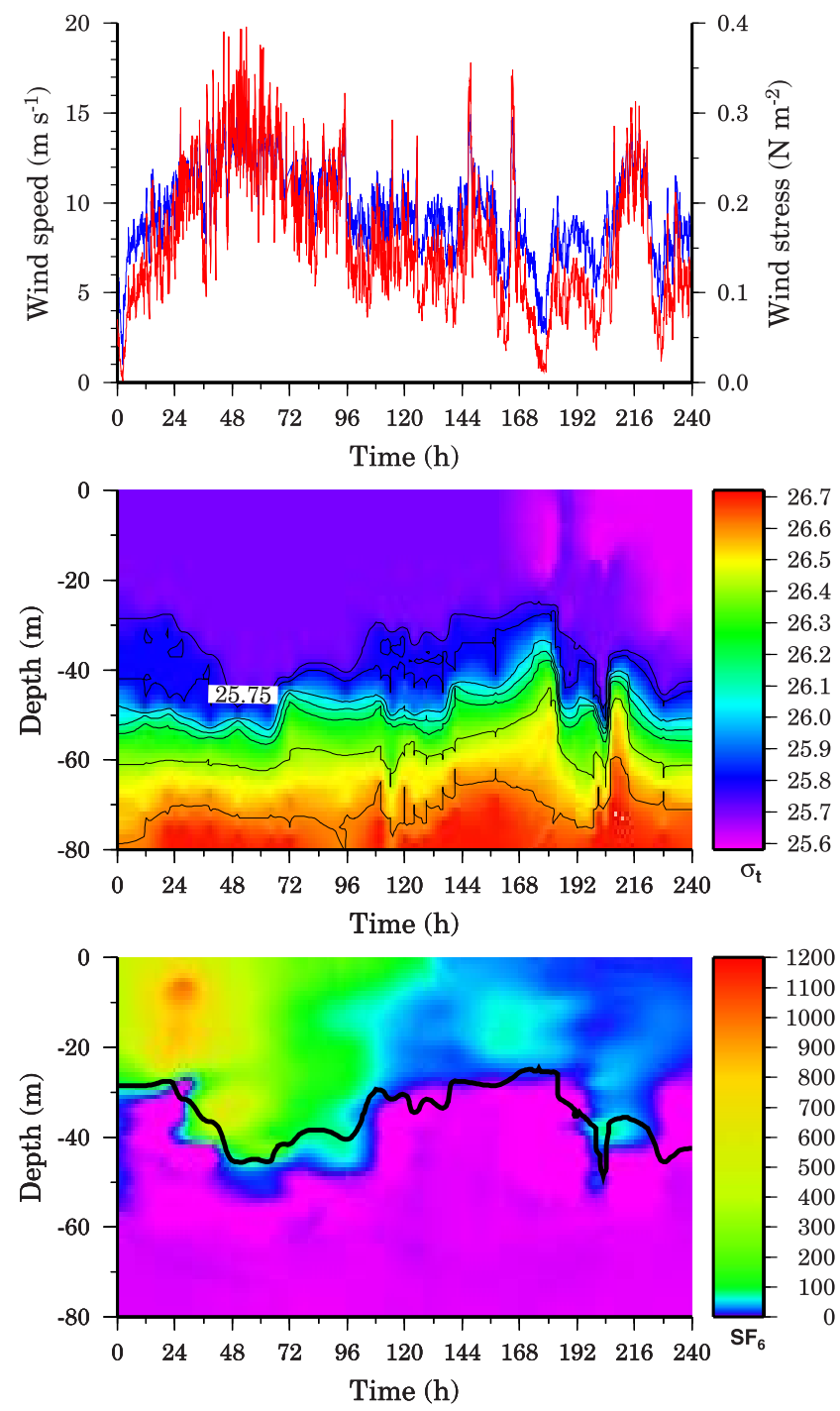

Figure 6. (top) Wind speed and wind stress during the FeCycle experiment. (middle) Temporal evolution of upper water column density $\left(\sigma_{\mathrm{t}}\right)$ at in patch stations during FeCycle. (bottom) Temporal evolution of $\mathrm{SF}_{6}\left(\mathrm{fmol} \mathrm{L}^{-1}\right)$ within the FeCycle patch. Purple indicates $\mathrm{SF}_{6}$ at preinfusion levels. The black line indicates the $\sigma_{\mathrm{t}}=25.75$ contour.

chlorophyll concentrations in the study region rising to over $1 \mu \mathrm{g} \mathrm{L}^{-1}$ overall and included some areas near $2 \mu \mathrm{g} \mathrm{L}^{-1}$. The light climate during FeCycle was typical of summer conditions with the PAR euphotic depth (1\% light level) changing little throughout FeCycle, $\sim 50 \mathrm{~m}$, despite a doubling in the chlorophyll concentration. The $1 \%$ light level for UV radiation was also relatively constant; $\lambda=$ $305 \mathrm{~nm}$ at $\sim 13 \mathrm{~m}, \lambda=320 \mathrm{~nm}$ at $\sim 20 \mathrm{~m}, \lambda=340 \mathrm{~nm}$ at $\sim 27 \mathrm{~m}$ and $\lambda=380 \mathrm{~nm}$ very similar to PAR at $\sim 50 \mathrm{~m}$.

[29] During a time series study taken over a diel cycle on 7 February (Figure 7) there was a strong cycle of surface cooling during the morning and evening and warming during the day $\left(\Delta \mathrm{T} \sim 0.15^{\circ} \mathrm{C}\right)$ with a minimum around dawn and maximum in the midafternoon. This surface temperature forcing is reflected in the AML and MLD which shallowed from a maximum at dawn to a minimum by midafternoon with a progression throughout the sunlit period as evidenced by the formation of 'steps' in the density profile. The SML during this time was relatively constant though there was possibly some internal wave activity. Strongest mixing appeared to be from nighttime convection as seen commonly in the tropical ocean [McNeil and Farmer, 1995]. About this time the upper part $(0-30 \mathrm{~m})$ of the patch apparently began to slip and move out over adjacent out patch waters. A second diel day on 11 February (not shown) had a smaller diel heating cycle $\left(\Delta \mathrm{T} \sim 0.10^{\circ} \mathrm{C}\right)$ and the vertical mixing appeared to be affected by increased wind mixing in the late afternoon (Figure 6) and changes in the MLD inconsistent with thermal heating/cooling and more likely from advection of different surface waters.

\subsection{Iron Distributions in the FeCycle Patch}

[30] The Fe distribution in the FeCycle patch is complicated by the discrepancies between the two methods employed for Fe measurement (auxiliary material Table S1). There was no statistically significant relationship between the FIA chemiluminescence system (hereafter referred to as the FIA data) and the GFAA data set (hereafter referred to as the GFAA data). Work on subsequent cruises in the Atlantic (P. L. Croot, manuscript in preparation, 2007) where identical samples were analyzed in the laboratory by GFAA and at immediately at sea and subsequently in the laboratory using this sulfite Fe(II) FIA technique [Bowie et al., 1998], however have identified a potential bias in surface water from the photic zone with high $\mathrm{H}_{2} \mathrm{O}_{2}$ concentrations $(>30 \mathrm{nM})$ and 8HQ columns [Landing et al., 1986]. This bias was reduced with increased sample storage time, by performing the technique of standard additions to each sample and by using the revised $8 \mathrm{HQ}$ column recipe [Dierssen et al., 2001]. The exact chemical nature of this bias is not yet identified but may be related to the presence of $\mathrm{Cu}(\mathrm{I})$ or $\mathrm{Mn}$ redox species when sulfite is used. This bias has so far not been observed in samples analyzed using the $\mathrm{Fe}(\mathrm{III})-\mathrm{H}_{2} \mathrm{O}_{2}$ Luminol technique [de Jong et al., 1998; Obata et al., 1993].

[31] The FeCycle data appear to be similarly biased as the DFe GFAA data (Figure 8) are consistently low throughout the mixed layer $(<70 \mathrm{pM})$ and are close to, or at, the detection limit of the technique (42 pM). There is no statistically significant variation in this data when measurement precision is taken into consideration. However, the FIA data indicate a surface enrichment of iron and for an overall increase throughout the experiment in the mixed layer. Only samples from below the mixed layer using the GO-FLOs for DFe show better agreement between the two techniques and do not statistically differ from each other (students paired t-test: $\mathrm{n}=5, \mathrm{t}=1.49, \mathrm{t}_{\text {crit }}=2.78$ at $95 \%$ confidence interval) though the value of this significance is limited by the small data set. Both data sets show a gradual increase in DFe with depth. The general trend of the GFAA measuring slightly higher values for Fe than the FIA method is also consistent with recent work in the Atlantic, where comparisons were made on samples with low $\mathrm{H}_{2} \mathrm{O}_{2}$ measured by onboard FIA measurements and laboratory GFAA analysis (P. L. Croot, manuscript in preparation, 2007) which suggest that when longer acidification times are used more iron is released from colloidal matrices. The GO-FLO samples were collected using the same handling and filtration procedures for both analysis techniques and so are the 

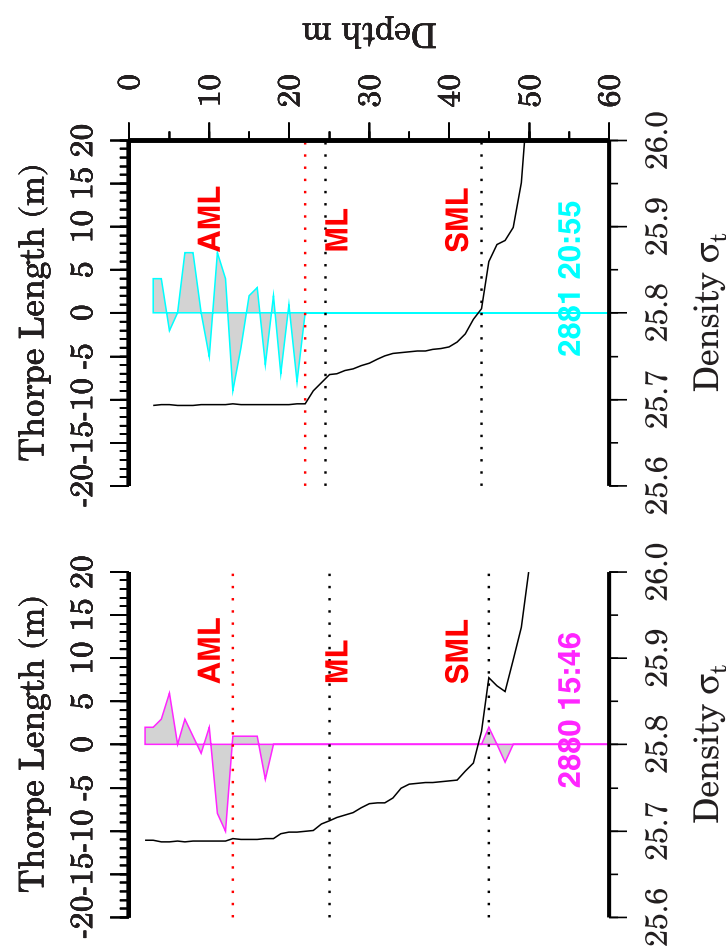

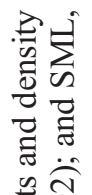

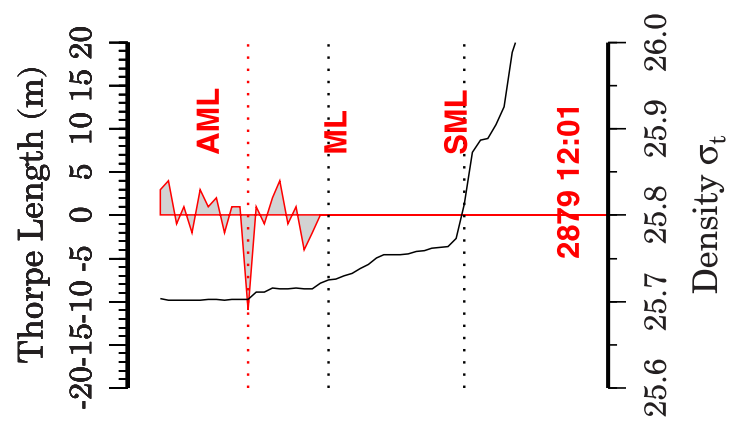

चํ.

ฮี 1

帝

힣

형

뭉

sì

总

है

总

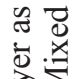

灾

롱

肴安

导

के

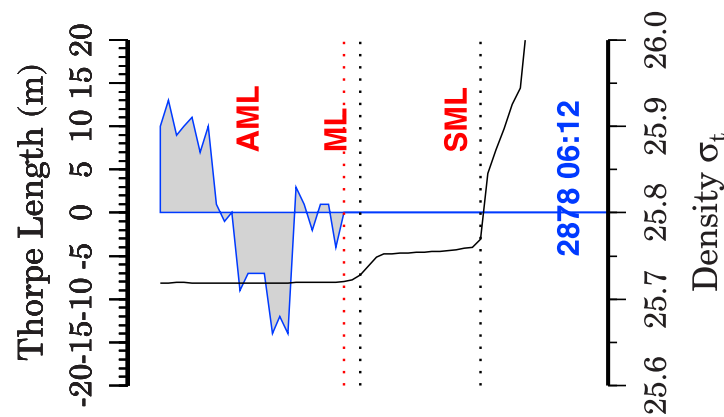

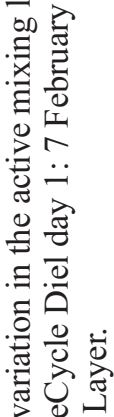

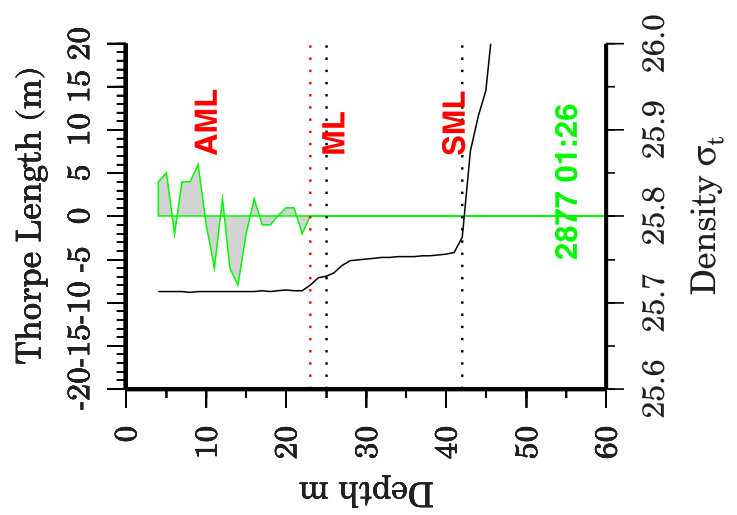

里

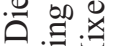

들

要

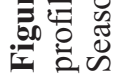



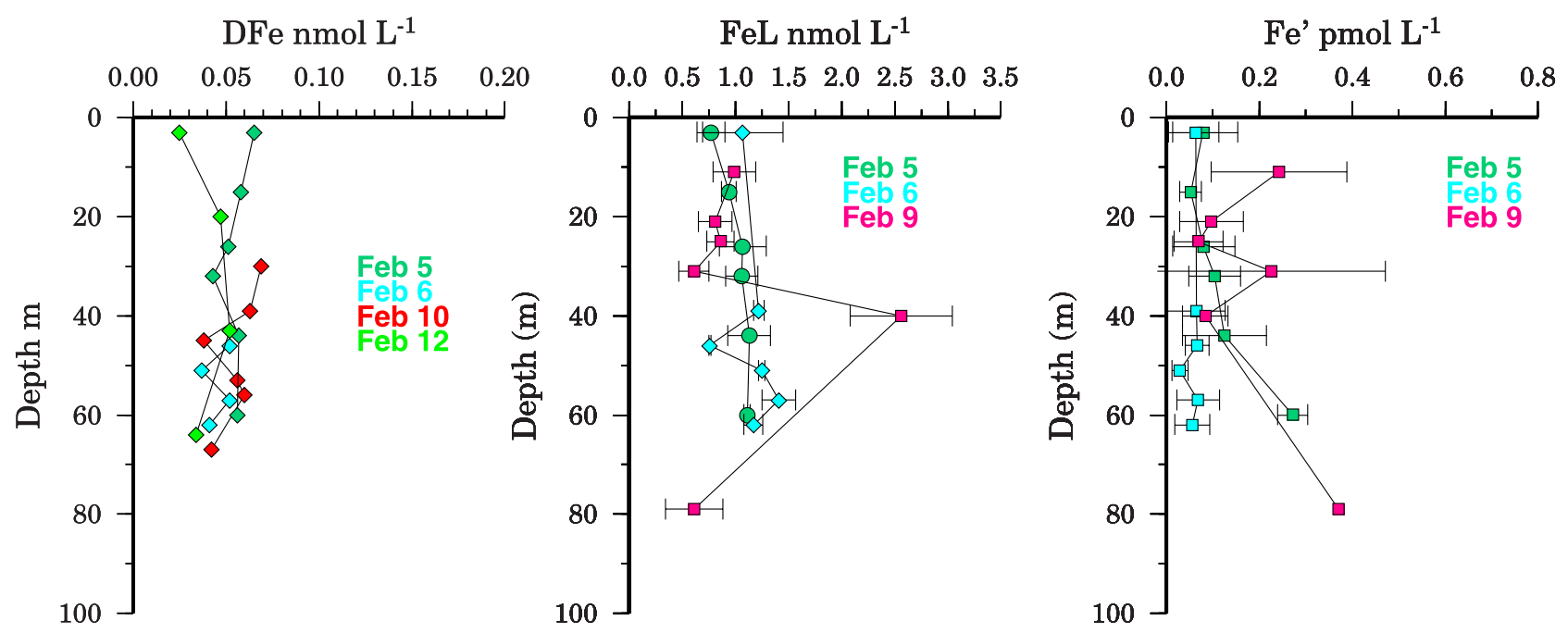

Figure 8. Vertical profiles of Fe species during FeCycle. (left) GFAA DFe during FeCycle. (middle) Total concentration of Iron binding ligands (FeL). (right) Estimated equilibrium concentration of inorganic iron $\left(\mathrm{Fe}^{\prime}\right)$. For all plots, data from each sampling day are represented by the same symbols: 5 February (circles), 6 February (diamonds), 9/10 February (squares), and 12 February (triangles).

only direct sample comparisons we have available. Thus for the purposes of the biogeochemical iron budget in FeCycle we only use the GFAA data set. A full analysis of the reasons for the differences in DFe between methods is beyond the scope of the present work and it is through international intercalibration exercises (see Bowie et al. [2006] and the recent SAFE cruise) where several different methods are compared that the answers to these problems will be solved.

\subsection{FeL and Fe(II) During FeCycle}

[32] Throughout FeCycle there was an excess of $\mathrm{L}$ (Figure 8) over the ambient DFe, as observed in other non iron enrichment open ocean studies [Boye et al., 2001; Croot et al., 2004b; Rue and Bruland, 1995]. Values were typically around $1 \mathrm{nM}$ in the upper water column throughout FeCycle with resulting $\mathrm{Fe}^{\prime}$ levels of $\sim 0.03-0.37 \mathrm{pM}$. The vertical distribution of [L] showed a slight increase with depth on 5 February, possibly related to photochemical destruction of the ligands [Barbeau et al., 2001; Powell and Wilson-Finelli, 2003] though the AML was then $\sim 40 \mathrm{~m}$ requiring a rapid photolysis rate. On 9 February [L] was relatively constant in the top $30 \mathrm{~m}$ with a single high value at $40 \mathrm{~m}$ which was just below the MLD and coincident with the bottom of a colder water layer recently been overlaid by the $\mathrm{SF}_{6}$ patch, suggestive of release of $\mathrm{L}$ from accumulated material on a density layer or grazing [MacIntyre et al., 1995].

[33] Underway surface measurements of Fe(II) were made on 5 occasions during FeCycle and at all times there was an apparent low background signal equivalent to $\sim 25 \mathrm{pM}$ $\mathrm{Fe}(\mathrm{II})$ above the reagent baseline. Measured $t_{1 / 2}$ for $\mathrm{Fe}$ (II) added to samples were remarkably short, $76-280 \mathrm{~s}$. The combination of low $\mathrm{Fe}(\mathrm{II})$ signals and rapid oxidation kinetics makes it difficult to categorically assign the observed chemiluminescence signal to that of solely Fe(II) as the $90 \mathrm{~s}$ between samples was too long to accurately observe decay of the ambient $\mathrm{Fe}(\mathrm{II})$ signal. At these low levels the detection/interference of $\mathrm{O}_{2}^{-}$in the seawater is potentially possible; where it could be present at 1-20 pM concentrations for steady state conditions, depending on sunlight, dissolved organic matter [Goldstone and Voelker, 2000] and $\mathrm{Cu}$ speciation [Zafiriou et al., 1998]. During FeCycle there was no statistically significant relationship between observed surface Fe(II) values and the PAR flux, but in a separate series of incubation experiments with added $\mathrm{Fe}$ and ligands (2nM, as 1:1.5 Fe:FeEDTA; other ligands also added), there was an apparent diel cycle $(50-100 \mathrm{pM})$ in Fe(II) (P. W. Boyd et al., unpublished data, 2003).

\section{Discussion}

\subsection{Physics of the $\mathrm{SF}_{6}$ Patch}

[34] Understanding the physical development of the FeCycle patch is central to interpreting the changes in the other measured parameters during the experiment. The changes in the patch dimensions induced by mixing and stirring necessitate the use of a tracer to follow the intricacies of these processes; without the use of the inert tracer $\mathrm{SF}_{6}$ in the present work we would not be able to follow these processes at all and subsequently there would be no framework to interpret the results for the other measured parameters in FeCycle.

\subsubsection{Temporal Evolution of the FeCycle Patch}

[35] From analysis of the $\mathrm{SF}_{6}$ and $\mathrm{T} / \mathrm{S}$ data 4 distinct phases in the development and mixing of the patch can be discerned.

[36] 1. Wind induced mixing (Figure 6) occurs over the first 48-60 hours resulting in $\mathrm{SF}_{6}$ being mixed down to $\sim 50$ where a salinity minimum apparently prevented deep mixing at this time.

[37] 2. There is a stable period ( $t=69-120$ hours) for 2-3 days as the patch drifts slowly south. Mixing with outside waters appeared to be a linear combination of the original patch water admixing with surrounding warmer, saltier surface waters based on $\mathrm{T} / \mathrm{S}$ properties (Figure 5).

[38] 3. The upper part $(0-30 \mathrm{~m})$ of the $\mathrm{SF}_{6}$ patch $(\mathrm{t}=120$ to 200 hours) begins to accelerate to the southeast with 

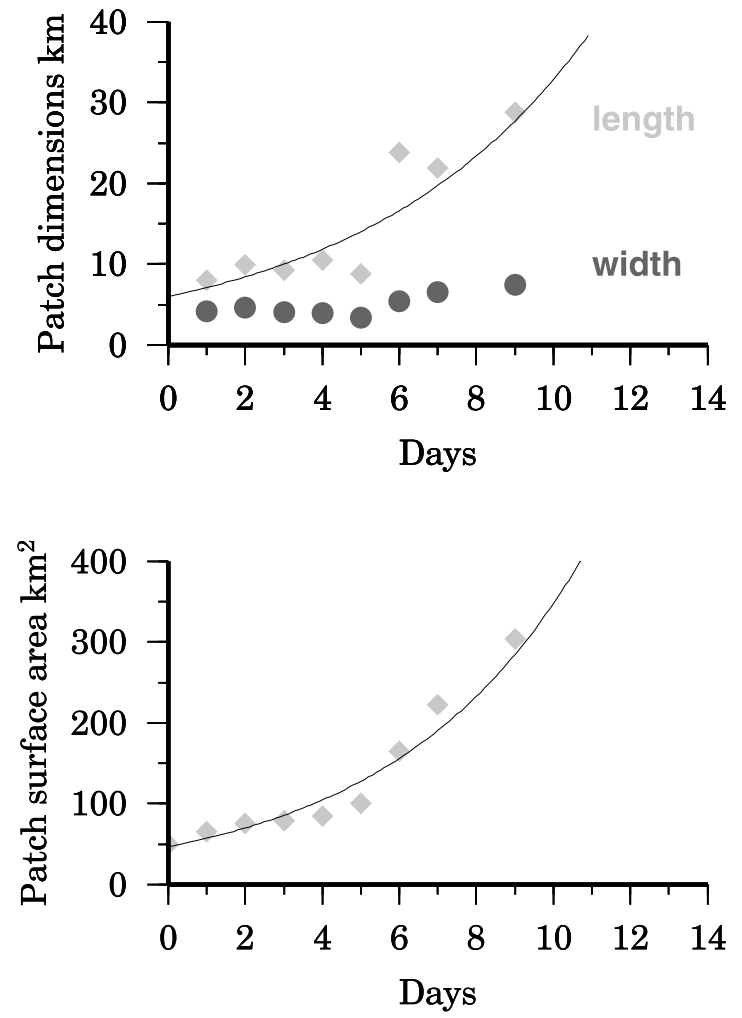

Figure 9. (bottom) Temporal changes in surface area of the $\mathrm{SF}_{6}$ patch during FeCycle. (top) Growth of the $\mathrm{SF}_{6}$ patch dimensions, length and width, during FeCycle. The area, length, and width of the patch were estimated by fitting ellipsoids to the Lagrangian corrected $\mathrm{SF}_{6}$ data shown in Figure 4.

resulting shear and slippage between surface layers. The result is the upper layer at the head of the patch now overlays non $\mathrm{SF}_{6}$ infused waters with a resulting decrease in the TLD. In the tail of the patch, warmer less dense waters from outside replace the upper part of the patch that has advected away, effectively capping the lower waters $(30-50 \mathrm{~m})$ of the SML which contained $\mathrm{SF}_{6}$. The result is a distinct $\mathrm{SF}_{6}$ maximum at depth in the tail of the patch.

[39] 4. The patch accelerates again ( $t=200$ to 250 hours) and moves northeast as it is unable to cross a strong temperature front to the south, possibly related to the presence of an eddy (Figure 1).

[40] The beam attenuation coefficient $\left(c_{\mathrm{p}}\right)$ data were used as a proxy for Particulate Organic Carbon (POC) [Gardner et al., 2003] to examine whether the increase in chlorophyll observed during FeCycle [McKay et al., 2005] was related to admixing with higher chlorophyll containing waters from outside the initial $\mathrm{SF}_{6}$ patch. During the first 2 phases of patch evolution a mixing gradient for POC between the initial $\mathrm{SF}_{6}$ patch $\left(c_{\mathrm{p}} \sim 0.08\right)$ and out patch waters $\left(c_{\mathrm{p}}>\right.$ $0.08)$ was apparent. Satellite data from 1 February 2003 support this as the initial FeCycle patch (station 28642867) was a minimum in surface chlorophyll with higher values to the north, east and to the south where the patch was drifting to (Figure 2). Later on (10/11 February) in the tail of the patch the $\mathrm{SF}_{6}$ maximum was at $\sigma_{\mathrm{t}} \sim 25.73$ with identical $c_{\mathrm{p}}$ values $(0.16)$ with higher values of $c_{\mathrm{p}}(0.18-$
0.20 ) in the overlying water. This suggests, on comparison with surface $\mathrm{SF}_{6}$ maps (Figure 4), that this water may have been subducted as early as the 7/8 February 2003 (see also Figure 5, the second plot) consistent with our estimation of the beginning of phase 3 of the patch evolution.

4.1.2. Horizontal and Vertical Mixing in the FeCycle Patch

[41] The FeCycle patch (Figure 4) developed into a filament where the width remained constant and the patch stretched exponentially lengthwise as expected for an isolated patch of conserved tracer in flow field away from frontal systems and observed early in SOIREE [Abraham et al., 2000]. Analysis of the Lagrangian corrected $\mathrm{SF}_{6}$ mappings by fitting elliposoids to the patch shape, where adequate closure of the patch boundaries was obtainable, allowed the estimation of the patch width, length and overall area as a function of time (Figure 9). As expected from the theory of dispersion of a tracer in a pure strain flow [Abraham et al., 2000] the patch width was restricted to $\sim 7 \mathrm{~km}$ while the length exponentially increased at the strain rate $\gamma$. During FeCycle, $\gamma=0.20 \pm 0.02 \mathrm{~d}^{-1}(\mathrm{n}=8, \mathrm{R}=0.97)$, based on the area of the patch with $\gamma=0.17 \pm 0.03 \mathrm{~d}^{-1}(\mathrm{n}=8$, $\mathrm{R}=0.90$ ) using patch length. For SOIREE [Abraham et al., 2000] $\gamma=0.07 \mathrm{~d}^{-1}$, indicating that the FeCycle patch was being diluted at $2-3$ times the rate found in SOIREE.

[42] The vertical diffusion constant, $\mathrm{K}_{\mathrm{Z}}$, for diffusion across the pycnocline was also estimated using $\mathrm{SF}_{6}$, however in the present work this estimate is complicated by the overlaying of surface water masses that occurred during this experiment, for this reason an estimate of $\mathrm{K}_{\mathrm{Z}}$, by secondmoment integrals of the $\mathrm{SF}_{6}$ distribution [Law et al., 2003] is limited to analysis of the first 4 days of the experiment when wind induced mixing was prevalent. Using this approach we obtain a value of $0.66 \pm 0.11 \mathrm{~cm}^{2} \mathrm{~s}^{-1}$ for $\mathrm{K}_{\mathrm{Z}}$ at the TLD for the first 4 days of FeCycle. After this time, estimates for $\mathrm{K}_{Z}$ were made using the relationship between $\mathrm{N}^{2}$ (the square of the Brunt-Vaisala buoyancy frequency) and $\mathrm{K}_{\mathrm{Z}}$ developed by Law et al. [2001] and extended by Law et al. [2003], compiled from earlier $\mathrm{SF}_{6}$ work. Using this approach gives an average for $\mathrm{K}_{\mathrm{Z}}$ of $1.16 \mathrm{~cm}^{2} \mathrm{~s}^{-1}\left(\log 10 \mathrm{~N}^{2}=-4.12\right)$ at the TLD from CTD data for the period of FeCycle. However, application of the revised relationship from Law et al. [2003] suggests a wide variability in the $\mathrm{N}^{2}$ based estimate at the TLD for $\mathrm{K}_{\mathrm{Z}}$ of $0.34-4.04 \mathrm{~cm}^{2}$ $\mathrm{s}^{-1}$, with most of this variability arising from the wide range of $\mathrm{K}_{\mathrm{Z}}$ values generated in previous tracer experiments performed in different oceanographic environments.

[43] The $\mathrm{SF}_{6}$ derived $\mathrm{K}_{\mathrm{Z}}$ estimates for FeCycle span the range for estimates made during other $\mathrm{SF}_{6}$ infusions: SOIREE, Southern Ocean, $0.11 \pm 0.2 \mathrm{~cm}^{2} \mathrm{~s}^{-1}$ [Law et al., 2003] and IRONEX, Equatorial Pacific, $0.25 \mathrm{~cm}^{2} \mathrm{~s}^{-1}$ [Law et al., 1998] and the PRIME experiment in the North Atlantic, $1.95 \mathrm{~cm}^{2} \mathrm{~s}^{-1}$ [Law et al., 2001]. Thorpe displacements can also be used to estimate $\mathrm{K}_{\mathrm{Z}}$ (see [Cisewski et al., 2005] and references therein) throughout the water column. Estimates of $\mathrm{K}_{\mathrm{Z}}$ using this approach are more variable as they are related to shorter timescales than $\mathrm{SF}_{6}$ measurements: A wide range of $10-150 \mathrm{~cm}^{2} \mathrm{~s}^{-1}$ is found in the AML and through the pycnocline $0.3-2.47 \mathrm{~cm}^{2} \mathrm{~s}^{-1}$ (based on $\mathrm{K}_{\mathrm{Z}}$ to $\mathrm{N}^{2}$ relationship [Law et al., 2003]). Mixing times for convective overturns in the AML, and elsewhere can then be estimated from $\mathrm{K}_{\mathrm{Z}}$ [Denman and Gargett, 1983; 
Table 1. Dissolved Iron Inventories During FeCycle ${ }^{\mathrm{a}}$

\begin{tabular}{ccc}
\hline Sample Period Date & TLD, $\mathrm{m} / 60 \mathrm{~m}$ & (GFAA) DFe, $\mu \mathrm{mol} \mathrm{m}^{-2}$ \\
\hline 5 Feb 2003 & $42 \mathrm{TLD}$ & $2.3 \pm 0.8$ \\
& 60 & $3.3 \pm 0.8$ \\
10 Feb 2003 & 57 TLD & $3.6 \pm 0.8$ \\
& 60 & $3.6 \pm 0.8$ \\
\hline
\end{tabular}

${ }^{\mathrm{a}}$ Vertically integrated iron inventories were estimated using the trapezoidal rule over the depth range where $\mathrm{SF}_{6}$ concentrations were above the out patch background $\left(>2 \mathrm{fmol} \mathrm{L}{ }^{-1}\right)$. Inventories were estimated from the surface to the TLD (patch) and to the salinity minimum or seasonal mixed layer (SML) at $60 \mathrm{~m}$. Error estimates $(2 \sigma)$ were constructed assuming no error for the depth values and using the $3 \sigma$ detection limit (GFAA) for the error in the iron value.

MacIntyre, 1998] ( $\tau_{\text {mix }}=\ell^{2} / 2 \mathrm{~K}_{\mathrm{Z}}$, where $\ell=$ the length of the overturn). During FeCycle $\tau_{\text {mix }}$ varied according to the immediately preceding surface forcing, ranging from 1 to 34 hours for the AML, with longer times for convective overturns below but still within the MLD. Thus biogeochemical processes that occur on faster timescales would not be well mixed through the MLD.

\subsection{Water Column Distribution of Iron}

[44] Water column inventories for DFe were estimated for 2 periods during FeCycle to both the TLD and the SML (Table 1). Comparison of the GFAA data indicate that there was no statistically significant increase in DFe for patch waters during FeCycle Interestingly however through 9 February there was an apparent intrusion of a warmer $\left(14.1^{\circ} \mathrm{C}, \mathrm{S}=34.34\right)$ saltier high chlorophyll containing surface water creating a shallow mixed layer $(\sim 20 \mathrm{~m})$ and mixing zone to cooler water $\left(13.5^{\circ} \mathrm{C}, \mathrm{S}=34.33\right)$ in another well mixed layer (30-40 $\mathrm{m}$ deep) which contained no added
$\mathrm{SF}_{6}$. Thus during this time DFe stayed apparently constant while chlorophyll levels increased.

\subsection{Mixing and Iron Supply to the FeCycle Patch 4.3.1. Dissolved Fe Fluxes From Depth Into the SML/WML}

[45] Estimating the diapycnal flux of DFe in/out of the tracer patch is complicated by the lack of a vertical gradient in DFe across the TLD or SML. The start of the ferricline was related to the depth of the WML (salinity maximum; see Figure 10) and to the base of the steepest section of the nutricline running from the AML to the WML. The diapycnal flux across the apparent ferricline (depth $\sim 121 \pm 6$ $(1 \sigma) \mathrm{m})$ was estimated in this work by two methods (Table 2). The first method uses a curve fitting approach (Table 2) used in early work by other researchers in the Black Sea [Lewis and Landing, 1991] and produces a smoothly varying profile. The second method used was the more common method of linearly estimating the slope in the $\mathrm{Fe}$ profile below the ferricline [Martin and Gordon, 1988]. Using the second method results in a constant $\delta \mathrm{Fe} / \delta \mathrm{z}$ throughout the ferricline, while the first method allows it to vary continuously. The second method assumes that the conditions of constant $\delta \mathrm{Fe} / \delta \mathrm{z}$ also applies at the top of the ferricline boundary, but reduces to 0 above it, while the first method allows it to vary throughout the vertical column. The resulting diapycnal flux estimates (Table 2) for the supply of Fe from below into the WML are probably more representative of the longer-term supply of $\mathrm{Fe}$ in the absence of atmospheric deposition, upwelling and the possible entrainment of coastal water to this site. Our estimates are on the higher side, $3.9-7.8 \mu \mathrm{mol} \mathrm{m}{ }^{-2} \mathrm{yr}^{-1}$ to those recently estimated for other HNLC regions: Southern ACC at $6^{\circ} \mathrm{W}\left(5.8 \mu \mathrm{mol} \mathrm{m}{ }^{-2} \mathrm{yr}^{-1}\right)$ [Löscher et al.,
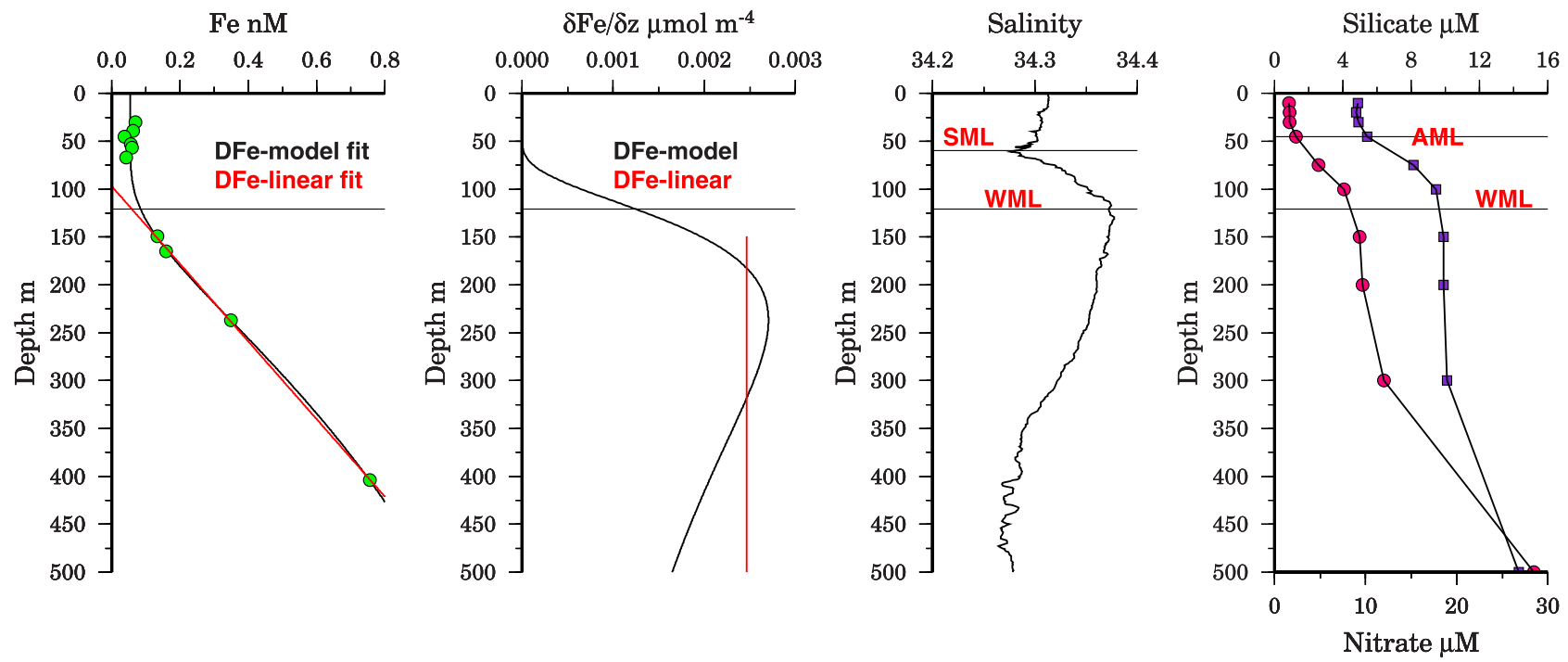

Figure 10. Modeling dissolved Fe fluxes and determining the depth of the Ferricline. (first plot) Dissolved iron data (circles) and results of the curve fitting (model 1; see Table 2) and linear fit (model 2) to the data set; (second plot) $\delta \mathrm{Fe} / \delta \mathrm{z}$ as a function of depth using the two different fitting models described in Table 2; (third plot) salinity at Station 2888, and (fourth plot) silicate (circles) and Nitrate (squares) concentrations at Station 2888. For all four plots the approximate depth of the top of the ferricline (depth of the Winter Mixed Layer (WML)) is marked with a horizontal dashed line. The depths of the AML (Active Mixed Layer), and SML (Seasonal Mixed Layer) are also shown. 
Table 2. Dissolved Iron Profile: FeCycle Fitting and Flux Estimate

\begin{tabular}{cccccc}
\hline \hline$[\mathrm{M}]$ & $\mathrm{A}$ & $\mathrm{B}$ & $\mathrm{C}$ & $\mathrm{D}$ & $\mathrm{E}$ \\
\hline $\mathrm{DFe}(\mathrm{nM})$ & $2.2 \pm 0.6$ & $20 \pm 9$ & $-272 \pm 372$ & $2.99 \pm 0.16$ & $0.055 \pm 0.005$ \\
\hline & & & Derivative Calculation & \\
\cline { 2 - 5 } Depth & Model & $\delta \mathrm{DFe} / \delta \mathrm{z}, \mathrm{nmol} \mathrm{m}^{-4}$ & $\mathrm{~K}_{\mathrm{z}}, \mathrm{m}^{2} \mathrm{~d}^{-1}$ & $\mathrm{DFe} \mathrm{Flux}^{2} \mathrm{nmol} \mathrm{m}^{-2} \mathrm{~d}^{-1}$ \\
\hline 120 & 1 & $1.22 \pm 0.04$ & $8.64 \pm 1.73$ & $10.5 \pm 2.1$ \\
120 & 2 & $2.47 \pm 0.04$ & $8.64 \pm 1.73$ & $21 \pm 4$ \\
\hline \hline
\end{tabular}

${ }^{\mathrm{a}}$ The dissolved Fe profile (all data) was fitted to the equation [Lewis and Landing, 1991]: [M] $=A \exp \left(\frac{-(B z-C)^{2}}{{ }^{2} D}+E\right.$. Fitting was performed using the nonlinear least squares Levenberg-Marquadt algorithim implemented using a Labview ${ }^{\mathrm{TM}}$ vi (National Instruments) which returned $\chi^{2}$ and error estimates for each parameter $(1 \sigma)$. The derivative of $[\mathrm{M}]$ with depth $(\mathrm{z})$, via the quotient rule is then (Model 1) $\frac{\partial[M]}{\partial z}=\left(\frac{z^{D}(2 B(C-B z))+D z^{(D-1)}(B z-C)^{2}}{\left(z^{D}\right)^{2}}\right) A$ exp $\left(\frac{-(B z-C)^{2}}{z^{D}}\right)$. Alternatively, $\delta \mathrm{DFe} / \delta \mathrm{z}$ was estimated using the linearly increasing DFe profile below $149 \mathrm{~m}\left(\mathrm{model} 2: \mathrm{R}^{2}=0.9995, \mathrm{n}=4\right) ;$ this results in a constant $\delta \mathrm{DFe} / \delta \mathrm{z}$ value for these depths. An average $\mathrm{N}^{2}$ estimate for $\mathrm{K}_{\mathrm{Z}}=1 \pm 0.2 \mathrm{~cm}^{2} \mathrm{~s}^{-1}$ at the depth of the ferricline (120 m).

1997], pre Fe infusion SOIREE $=1.1 \mu \mathrm{mol} \mathrm{m}{ }^{-2} \mathrm{yr}^{-1}[$ Law et al., 2003], preinfusion EisenEx $=0.63 \mu \mathrm{mol} \mathrm{m}^{-2} \mathrm{yr}^{-1}$ (P. L. Croot et al., Uncovering the fate of the iron during EISENEX, a Southern Ocean mesoscale iron enrichment experiment, submitted to Deep Sea Research, Part I, 2007), the Southern ACC at $6^{\circ} \mathrm{E}=1.5 \mu \mathrm{mol} \mathrm{m}^{-2} \mathrm{yr}^{-1}$ [Croot et al., 2004b] and at Ocean Station Papa $=0.04 \mu \mathrm{mol} \mathrm{m}{ }^{-2}$ $\mathrm{yr}^{-1}$ [Löscher et al., 1997].

\subsubsection{Possibility of Atmospheric Deposition of Iron Before and During FeCycle}

[46] Atmospheric dust source models indicate that the major source of dust to the FeCycle area is from the dry regions of Australia [Mahowald et al., 1999]. The wind transport of dust, soils, pollens and insects from Australia to New Zealand and the southwest Pacific is well described [Glasby, 1971; Sturman et al., 1997] Analysis of air mass trajectories indicate that over $80 \%$ of low-level air parcels from the Sydney area in summer pass over central New Zealand on average 5 days later, though this transit time can be as short as one and a half days [Sturman et al., 1997]. Dust flux estimates for this region are scarce but based on lithogenic Si sediment trap data in the same area [Nodder and Northcote, 2001] we estimate an Aeolian dust flux of $\sim 15-45 \mathrm{mg} \mathrm{Fe} \mathrm{m}^{-2} \mathrm{yr}^{-1}$ or $270-810 \mu \mathrm{mol} \mathrm{Fe} \mathrm{m}{ }^{-2} \mathrm{yr}^{-1}$ (assuming a crustal composition of Si:Fe of $\sim 6.67 \mathrm{~g} / \mathrm{g}$ [Wedepohl, 1995]). Global compilations and models suggest similar aeolian Fe fluxes of $250-750 \mu \mathrm{mol} \mathrm{m}^{-2} \mathrm{yr}^{-1}$ [Duce et al., 1991; Fung et al., 2000; Mahowald et al., 1999]. Combining these fluxes with estimates of aerosol solubility ( $1-4 \%$, if $\mathrm{pH}<3.7$ during transport) for Australian soils [Mackie et al., 2005] suggests a potential supply of dissolvable Fe to surface waters of $2.7-32 \mu \mathrm{mol} \mathrm{m}{ }^{-2} \mathrm{yr}^{-1}$.

[47] Satellite observations immediately prior to and during FeCycle showed the presence of dust/ash clouds derived from large bush fires in the south eastern states of Victoria and New South Wales in Australia, over parts of New Zealand (see above). From examination of satellite aerosol and back trajectory data (data not shown) we can identify two periods when atmospheric deposition to the FeCycle patch may have occurred: (1) 4-5 February and (2) 810 February. However, as no atmospheric aerosol samples were obtained in the present work, we have no direct evidence for aerosol deposition of iron only that it possibly occurred at this time. There is a strong case to be made for future work to include simultaneous atmospheric and oceanic measurements as recently performed in the Tropical Atlantic [Croot et al., 2004a].

\subsection{Cycling of $\mathrm{Fe}(\mathrm{II})$ and Fe Binding Ligands}

[48] In FeCycle, added Fe(II) was rapidly oxidized $\left(t_{1}<\right.$ $360 \mathrm{~s}, k_{\mathrm{ox}}>1.9 \times 10^{-3} \mathrm{~s}^{-1}$ : auxiliary material) consistent with laboratory data in this temperature range [King, 1998; Millero and Sotolongo, 1989; Millero et al., 1987] for Fe(II) oxidation by ambient $\mathrm{H}_{2} \mathrm{O}_{2}$; estimated at $40-70 \mathrm{nM}$ based on $\mathrm{t}_{1 / 2} \sim 240-420 \mathrm{~s}(\mathrm{pH}=8)$ and surface values for similar latitudes in the Atlantic [Weller and Schrems, 1993]. It is also possible that oxidation rates at ambient [Fe(II)] were slower than the added inorganic Fe(II) because some of the $\mathrm{Fe}(\mathrm{II})$ was organically complexed (see below). The issue of $\mathrm{Fe}(\mathrm{II})$ production during FeCycle is more complex as there are several possible mechanisms in surface seawater with photochemical production clearly important [Croot et al., 2001, and references therein] though it only occurs during sunlit hours. A long surface transect on the night of $8 / 9$ February indicated [Fe(II)] from 19 to $46 \mathrm{pM}$ (Figure 11); assuming this represents only inorganic $\mathrm{Fe}(\mathrm{II})$ and not $\mathrm{O}_{2}^{-}$ (see early), this would suggest a production rate $\leq 225 \pm$ $94 \mathrm{pM} \mathrm{h}^{-1}$, significantly higher than from measurements of the most likely dark process: biological reduction via ferric reductases [Maldonado and Price, 2000; Shaked et al., 2004]. This production rate for Fe(II) is much greater than the observed phytoplankton uptake of radioactive $\mathrm{Fe}$ complexed by the natural ligand assemblage in the dark $\left(0.5 \mathrm{pM} \mathrm{h}^{-1}\right)$ during FeCycle [Maldonado et al., 2005] suggesting there would need to be appreciable recomplexation and/or oxidation of bio-reduced Fe(II) [Shaked et al., 2005; Sunda, 2001]. Recent estimates for bio-reduction rates in the subarctic HNLC waters suggest $3-4 \mathrm{pM} \mathrm{h}^{-1}$ for algae $>5 \mu \mathrm{m}$ [Shaked et al., 2004], in FeCycle the

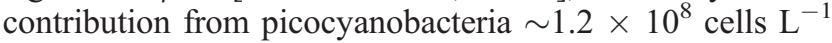
[McKay et al., 2005] may have seen higher reduction rates [Maldonado and Price, 2000; Sunda, 2001]. Assuming a similar bio-reduction rate of $3-4 \mathrm{pM} \mathrm{h}^{-1}$ to that measured by Shaked et al., for the total Fe(II) concentrations (inorganic and organic) and physical conditions observed in FeCycle would require the inclusion of $\sim 1 \mathrm{nM}$ of an $\mathrm{Fe}(\mathrm{II})$ complexing ligand under optimum conditions $\left(\mathrm{k}_{\mathrm{f}}=\right.$ $\left.1 \times 10^{6} \mathrm{M}^{-1} \mathrm{~s}^{-1}, \mathrm{k}_{\mathrm{d}}>1 \times 10^{-4} \mathrm{~s}^{-1}\right)$, present in seawater either as a dissolved or surface complex. Under these conditions approximately $26 \%$ of the inorganic Fe(II) produced would be organically complexed and the rest 

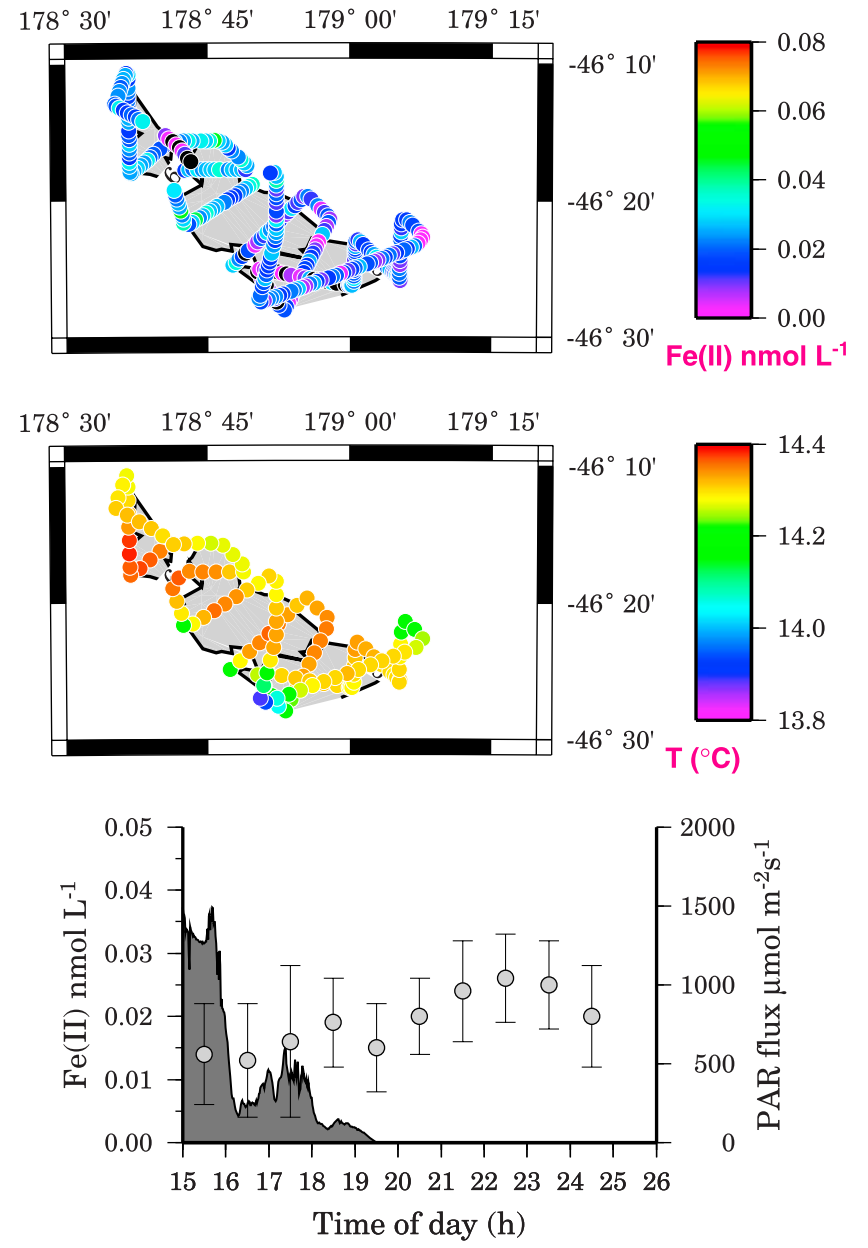

Figure 11. Surface transects of (top) Fe(II) and (middle) sea surface temperature during the mapping transect of $8 / 9$ February 2003. For both plots the surface expression of the $\mathrm{SF}_{6}$ patch is marked as the shaded gray region denoted by the $6 \mathrm{fmol} \mathrm{L}^{-1} \mathrm{SF}_{6}$ isoline. (bottom) Hourly $\mathrm{Fe}(\mathrm{II})$ data (circles) during the transect of $8 / 9$ February 2003. The data have been binned into hour sets, and the mean and standard deviation are shown for each hourly bin. The PAR flux (gray) is also shown for this time.

oxidized by $\mathrm{H}_{2} \mathrm{O}_{2}$ or $\mathrm{O}_{2}$. Thus the nighttime observation of $\mathrm{Fe}(\mathrm{II})$ at $\mathrm{pmol} \mathrm{L}^{-1}$ levels would strongly suggest the presence of $\mathrm{Fe}(\mathrm{II})$ organic ligands with important implications on the lifetime of these redox species in seawater and the overall bioavailability of Fe.

[49] Throughout FeCycle DFe was dominated by the presence of $\mathrm{Fe}$ (III) organic complexes which remained at $\sim 1 \mathrm{nM}$ throughout the experiment, consistent with other HNLC regions [Boye et al., 2001; Croot et al., 2004b, 2001; Rue and Bruland, 1995]. Equilibrium estimates of $\mathrm{Fe}^{\prime}$ ranged from 0.03 to $0.37 \mathrm{pM}$ typical of an iron limited HNLC system. The flux of $\mathrm{Fe}^{\prime}$ from ligand dissociation can be estimated from dissociation rate constants $\left(k_{\mathrm{d}}\right)$ for $\mathrm{FeL}$, using the determined $\log \mathrm{K}\left(\mathrm{K}=k_{\mathrm{f}} / k_{\mathrm{d}}\right)$ values, assuming $k_{\mathrm{f}}=$ $0.25 k_{-\mathrm{H} 2 \mathrm{O}}=2 \times 10^{6} \mathrm{~s}^{-1}$ [Hudson et al., 1992], giving $k_{\mathrm{d}}=$ $0.8-5.9 \times 10^{-6} \mathrm{~s}^{-1}$. Combining $k_{\mathrm{d}}$ with DFe data gives the steady state $\mathrm{Fe}^{\prime}$ flux from complex dissociation: $0.5-$ $3.6 \times 10^{-16} \mathrm{~mol} \mathrm{~L}^{-1} \mathrm{~s}^{-1}$.

\subsection{Turnover Times for $\mathrm{DFe}$ in the SML/WML}

[50] Calculation of a turnover time for DFe using the inventory in the SML (Table 1) with the strong Fe demand, [McKay et al., 2005] in the SML, indicates a turnover time for Fe within the SML of $\sim 1.1$ days (integrated uptake flux of DFe $\sim 3 \mu \mathrm{mol} \mathrm{m}^{-2} \mathrm{~d}^{-1}$ ) and $\sim 2.4$ days for the WML. An average residence time for $\mathrm{Fe}$ in the WML can be estimated as 340 (model 2) - 690 (model 1) days. Thus on average DFe is cycled through the biota 140-280 times before leaving the WML. To maintain this cycling rate requires fast conversion of iron in biota back to dissolved phases. Measurements of biologically mediated regeneration fluxes from FeCycle [Strzepek et al., 2005], confirm this rapid cycling of particulate iron to dissolved (assuming constant rates through the SML) with short turnover times: bacterivory 3.7 days (flux $1.7 \times 10^{-16} \mathrm{~mol} \mathrm{~L}^{-1} \mathrm{~s}^{-1}$ ), herbivory 14.8 days (flux $4.3 \times 10^{-17} \mathrm{~mol} \mathrm{~L}^{-1} \mathrm{~s}^{-1}$ ) and release via viral lysis $0.8-64$ days (flux $0.1-8 \times 10^{-16} \mathrm{~mol} \mathrm{~L}^{-1} \mathrm{~s}^{-1}$ ). Supply of DFe from the atmosphere would significantly reduce this residence time estimates. The DFe residence time for FeCycle is considerably shorter than that for the dust impacted, nitrogen limited, Tropical Atlantic (1-10 years [Croot et al., 2004a]) presumably owing to the low iron supply and high demand at the FeCycle site.

\subsection{Vertical Mixing During FeCycle: Importance to Biogeochemical Cycling}

[51] During FeCycle it was apparent that physical processes had stronger influences on Fe biogeochemical cycling but smaller effects on macronutrients such as nitrate [McKay et al., 2005]. To illustrate these differences we examine in detail Station 2906 (Figure 12) where differences in mixing rates saw vertical gradients in several biogeochemical parameters. The AML was at $\sim 18 \mathrm{~m}$ with 2 large overturns identifiable by CTD and $\tau_{\text {mix }} \sim 5$ hours; below this there was a small density gradient to the SML at $\sim 50 \mathrm{~m}$. The $1 \%$ light level for PAR was at $\sim 60 \mathrm{~m}$, indicating that algae throughout the MLD were not light limited. Short wavelength UV $(305-340 \mathrm{~nm})$ was not attenuated below $0.1 \%$ in the AML. The vertical distribution of phytoplankton (derived from fluorescence or transmission) was constant in the AML but peaked at around $30 \mathrm{~m}$ in the SML with 'step' like features in the profile, consistent with smaller overturns, as seen in the Thorpe displacements. The fluorescence maximum was also mirrored in the ammonia profile, while nitrate was relatively constant throughout the upper $30 \mathrm{~m}$ after which a strong vertical gradient developed. Accumulation of material at density discontinuities [MacIntyre et al., 1995] may explain the increase in Fe binding ligands in the lower part of the SML through the release of dissolved ligands from decaying matter. The high $\mathrm{SF}_{6}$ values at $40 \mathrm{~m}$ also suggest that this water had been at the surface several days early and that the lower part of the SML was mixing very slowly. Finally the divergence of the ratio of $\mathrm{SF}_{6}$ and $\mathrm{L}$ in the upper water column suggests mixing with out patch waters with slightly higher ligand concentrations or in situ production at rates faster than the $\tau_{\text {mix }}$. 

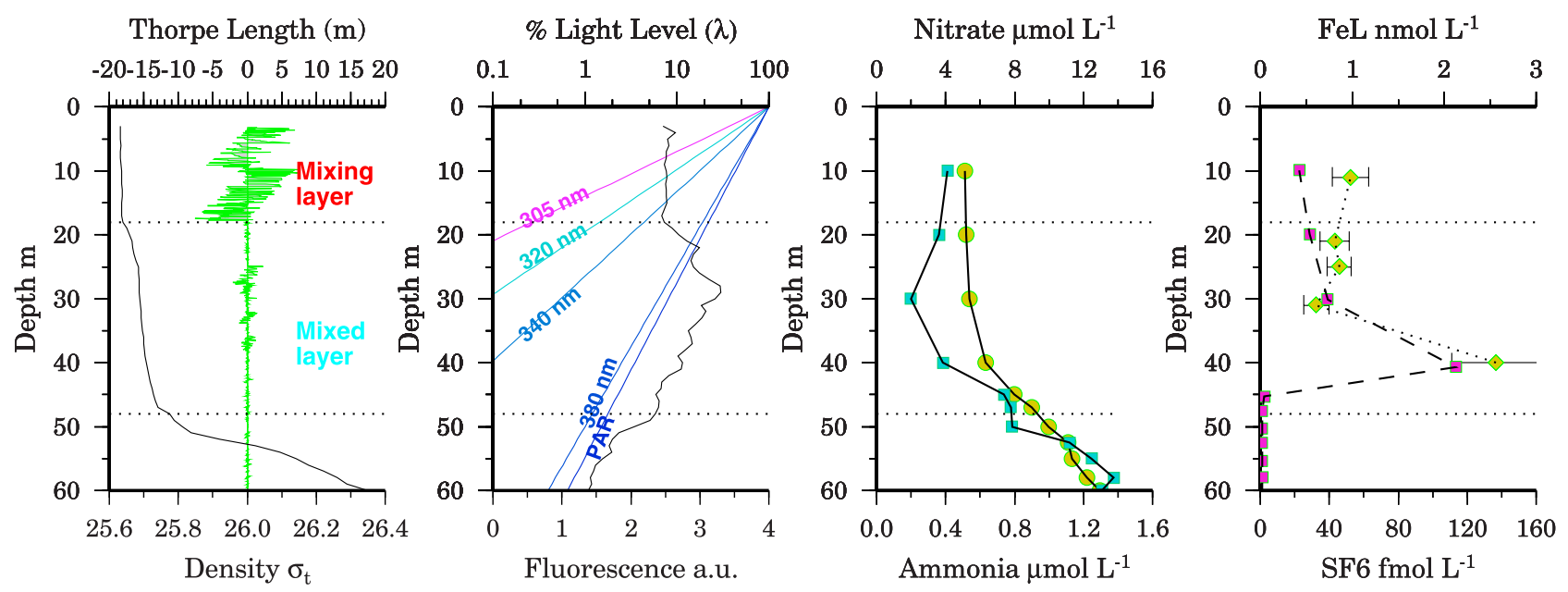

Figure 12. Effect of mixing dynamics on chemical parameters at station 2906 (10 February 23:54 NZST) during FeCycle. (first plot) Thorpe displacements (green) and density profile (black) showing the location of the mixing layer and the mixed layer at this time. (second plot) Fluorescence profile and light attenuation profiles for UV and PAR wavelengths. (third plot) $\mathrm{NO}_{3}$ (circles) and $\mathrm{NH}_{4}$ (squares) distributions. (fourth plot) $\mathrm{SF}_{6}$ tracer (squares) and $\mathrm{L}$ (diamonds).

\subsection{Deep Ferricline-Shallow Nitricline: Importance of Lateral Transport}

[52] During FeCycle the ferricline began at $\sim 120 \mathrm{~m}$, well below the SML and the nitracline $(\sim 50 \mathrm{~m})$ a situation that has been noted earlier in the central Pacific [Johnson et al., 1997b]. Johnson et al. [1997b] suggested that such features in the central Pacific were produced by the sinking of highnitrate, low-iron (HNLI) surface waters which are derived from higher latitudes where the thermocline outcrops during winter, this water is then laterally transported toward lower latitudes. As a biological response to this deep ferricline some diatoms in tropical waters may vertically migrate to obtain Fe from below the ferricline [McKay et al., 2000] potentially further deepening the ferricline. An iron biogeochemical model of the tropical Pacific [Christian et al., 2002] suggests that the ferricline is driven deeper than the nitracline by a greater biological demand for $\mathrm{Fe}$ than for Nitrogen with the result that ammonium accumulates in the upper water column. On longer temporal scales a biogeochemical model for the Equatorial Pacific suggests that the ferricline may deepen in response to a large-scale physical forcing such as El Niño [Wang et al., 2005].

[53] Data from FeCycle partially support aspects of these theories for ferricline development in midlatitudes, as HNLI surface waters overlaid each other throughout the SML (Figure 6) which were located above the euphotic depth (Figure 12) indicating that there was some phytoplankton demand for $\mathrm{Fe}$ immediately below the SML [see also McKay et al., 2005, Figure 4]. However, the key reason for the deeper ferricline in FeCycle appears to be the depletion of Fe from the WML in the spring but without the complete removal of the macronutrients (Figure 10). Aiding the development of a deeper ferricline is the remineralization length scale for $\mathrm{Fe}$ as compared to other nutrients [Dutkiewicz et al., 2005]. In FeCycle analysis of particles collected from floating sediment traps indicate that the remineralization length for $\mathrm{Fe}$ was located deeper than that of $\mathrm{C}$ and $\mathrm{N}$ [Frew et al., 2005]. This difference in remineralization lengths leads to, in the absence of any other sources of $\mathrm{Fe}$, a deeper ferricline than nitracline if vertical mixing is slow. Furthermore the accumulation of ammonium (Figure 12) in the SML probably reflects a high Fe demand in the SML by Fe poor phytoplankton [McKay et al., 2005; Strzepek et al., 2005] which is driven further to limitation by a low $\mathrm{Fe}: \mathrm{NO}_{3}^{-}$ratio $(11.9 \mu \mathrm{mol}: \mathrm{mol})$ in the diffusive supply from the deep; this is equivalent to an $\mathrm{Fe}: \mathrm{C}$ of $1.8 \mu \mathrm{mol}: \mathrm{mol}$ which is less than the size fractionated $\mathrm{Fe}: \mathrm{C}$ uptake ratios (5.5-19 $\mu \mathrm{mol}: \mathrm{mol})$ measured in FeCycle [McKay et al., 2005]. Additionally the differing chemistries between $\mathrm{Fe}$ and $\mathrm{N}$ sees much of the remineralized Fe readsorbing to sinking particles while the $\mathrm{N}$ is remineralized to dissolved forms [see Frew et al., 2005, Figure 5]. The position of the ferricline thus then depends on a complex balance between mixing, Fe demand, composition of the particulate matter, organic complexation and scavenging throughout the surface waters and supply via advection or atmospheric deposition.

\section{Conclusions}

[54] FeCycle is a first attempt at a comprehensive study of Fe cycling under ambient conditions in the open ocean. The FeCycle patch underwent dynamic physical mixing and was strongly affected by shear in the upper water column providing insights into the everyday processes that can alter phytoplankton productivity and iron biogeochemistry. Only through the use of the inert tracer $\mathrm{SF}_{6}$ we were able to follow these mixing processes and piece together the sequence of important physical processes on Fe cycling in surface waters. Importantly FeCycle showed that smallscale lateral variability (e.g., induced from atmospheric input) can exist on scales of tens of kilometers and such changes in a non-Lagrangian experiment would be typically interpreted as an apparent change in the biogeochemistry instead missing the true hydrodynamically driven nature of these changes.

[55] Results from FeCycle strongly suggest that only atmospheric supply of $\mathrm{Fe}$ could provide relief from chronic 
Fe limitation in this region. Future work on Fe budgets in the ocean need to examine carefully the relationship between mixing processes and the vertical distributions of Fe species and emphasis must also be placed on quantifying the atmospheric input to surface waters which is presently poorly understood on short temporal scales.

[56] Acknowledgments. We gratefully acknowledge the officers and crew of the R.V. Tangaroa whose help and cooperation made this work possible. Peter Hill and Jerram Robinson helped in the $\mathrm{SF}_{6}$ development and analysis. Special thanks go to Bill Landing for his helpful comments on this manuscript. Funding for this work was provided by the IFM-GEOMAR and CAU Kiel, University of Otago, NIWA, and the New Zealand Foundation for Research Science and Technology (FORST). P. L. C. acknowledges partial support of this work through the Deutsche Forschungsgemeinschaft (DFG) grants CR 145/5 and CR145/6, this work is also a contribution to the German SOLAS (SOPRAN) program.

\section{References}

Abraham, E. R., C. S. Law, P. W. Boyd, S. J. Lavender, M. T. Maldonado, and A. R. Bowie (2000), Importance of stirring in the development of an iron-fertilised phytoplankton bloom, Nature, 407, 727-730.

Anderson, M. A., and F. M. Morel (1980), Uptake of Fe (II) by a diatom in oxic culture medium, Mar. Biol. Lett., 1, 263-268.

Baith, K., R. Lindsay, G. Fu, and C. R. McClain (2001), SeaDAS: A data analysis system for ocean colour satellite sensors, Eos Trans. $A G U$, 82(18), 202

Banse, K., and D. C. English (1997), Near-surface phytoplankton pigment from the Coastal Zone Color Scanner in the subantarctic region southeas of New Zealand, Mar. Ecol. Prog. Ser, 156, 51-66.

Barbeau, K., E. L. Rue, K. W. Bruland, and A. Butler (2001), Photochemical cycling of iron in the surface ocean mediated by microbial iron (III)-binding ligands, Nature, 413, 409-413.

Bowie, A. R., E. P. Achterberg, R. F. C. Mantoura, and P. J. Worsfold (1998), Determination of sub-nanomolar levels of iron in seawater using flow injection with chemiluminescence detection, Anal. Chim. Acta, 361, $189-200$.

Bowie, A. R., et al. (2001), The fate of added iron during a mesoscale fertilisation experiment in the Southern Ocean, Deep Sea Res., Part II, $48,2703-2743$

Bowie, A. R., E. P. Achterberg, P. L. Croot, H. J. W. de Baar, P. Laan, J. W. Moffett, S. Ussher, and P. J. Worsfold (2006), A community-wide intercomparison exercise for the determination of dissolved iron in seawater, Mar. Chem., 98, 81-99.

Boyd, P. (2004), Ironing out algal issues in the Southern Ocean, Science, 304, 396-397.

Boyd, P. W., and E. R. Abraham (2001), Iron-mediated changes in phytoplankton photosynthetic competence during SOIREE, Deep Sea Res. Part II, 48, 2529-2550.

Boyd, P., J. LaRoche, M. Gall, R. Frew, and R. M. L. McKay (1999), Role of iron, light and silicate in controlling algal biomass in subantarctic waters SE of New Zealand, J. Geophys. Res., 104, 13,395-13,408.

Boyd, P. W., G. McTainsh, V. Sherlock, K. Richardson, S. Nichol, M. Ellwood, and R. Frew (2004), Episodic enhancement of phytoplankton stocks in New Zealand subantarctic waters: Contribution of atmospheric and oceanic iron supply, Global Biogeochem. Cycles, 18, GB1029, doi:10.1029/2002GB002020.

Boyd, P. W., et al. (2005), FeCycle: Attempting an iron biogeochemical budget from a mesoscale SF6 tracer experiment in unperturbed low iron waters, Global Biogeochem. Cycles, 19, GB4S20, doi:10.1029/ 2005GB002494.

Boye, M., C. M. G. van den Berg, J. T. M. de Jong, H. Leach, P. L. Croot, and H. J. W. de Baar (2001), Organic complexation of iron in the Southern Ocean, Deep Sea Res., Part I, 48, 1477-1497.

Brainerd, K. E., and M. C. Gregg (1995), Surface mixed and mixing layer depths, Deep Sea Res., Part I, 42, 1521-1543.

Bruland, K. W., R. P. Franks, G. A. Knauer, and J. H. Martin (1979), Sampling and analytical methods for the determination of copper, cadmium, zinc and nickel at the nanogram per liter level in seawater, Anal. Chim. Acta, 105, 233-245.

Christian, J. R., M. A. Verschell, R. Murtugudde, A. J. Busalacchi, and C. R. McClain (2002), Biogeochemical modelling of the tropical Pacific Ocean. II: Iron biogeochemistry, Deep Sea Res., Part II, 49, $545-565$

Cisewski, B., V. H. Strass, and H. Prandke (2005), Upper-ocean vertical mixing in the Antarctic Polar Front Zone, Deep Sea Res., Part II, 52 , $1087-1108$.
Croot, P. L., and K. A. Hunter (2000), Determination of Fe (II) and total iron in natural waters with 3-(2-pyridyl)-5,6-diphenyl-1,2,4-triazine (PDT), Anal. Chim. Acta, 406, 289-302.

Croot, P. L., and M. Johansson (2000), Determination of iron speciation by cathodic stripping voltammetry in seawater using the competing ligand 2-(2-Thiazolylazo)-p-cresol (TAC), Electroanalysis, 12(8), 565-576.

Croot, P. L., and P. Laan (2002), Continuous shipboard determination of Fe (II) in polar waters using flow injection analysis with chemiluminescence detection, Anal. Chim. Acta, 466, 261-273.

Croot, P. L., et al. (2001), Retention of dissolved iron and FeII in an iron induced Southern Ocean phytoplankton bloom, Geophys. Res. Lett., 28, $3425-3428$

Croot, P. L., P. Streu, and A. R. Baker (2004a), Short residence time for iron in surface seawater impacted by atmospheric dry deposition from Saharan dust events, Geophys. Res. Lett., 31, L23S08, doi:10.1029/ 2004GL020153.

Croot, P. L., K. Andersson, M. Öztürk, and D. Turner (2004b), The distribution and speciation of iron along $6^{\circ} \mathrm{E}$, in the Southern Ocean, Deep Sea Res., Part II, 51, 2857-2879.

Croot, P. L., et al. (2005), Spatial and temporal distribution of Fe (II) and $\mathrm{H}_{2} \mathrm{O}_{2}$ during EISENEX, an open ocean mesoscale iron enrichment, Mar. Chem., 95, 65-88.

Danielsson, L.-G., B. Magnusson, and S. Westerlund (1978), An improved metal extraction procedure for the determination of trace metals in sea water by atomic absorption spectrometry with electrothermal atomisation, Anal. Chim. Acta, 98, 47-57.

de Jong, J. T. M., J. den Das, U. Bathmann, M. H. C. Stoll, G. Kattner, R. F. Nolting, and H. J. W. de Baar (1998), Dissolved iron at subnanomolar levels in the Southern Ocean as determined by ship-board analysis, Anal. Chim. Acta, 377, 113-124.

Denman, K. L., and A. E. Gargett (1983), Time and space scales of vertical mixing and advection of phytoplankton in the upper ocean, Limnol. Oceanogr., 28, 801-815.

Dierssen, H., W. Balzer, and W. M. Landing (2001), Simplified synthesis of an 8-hydroxyquinoline chelating resin and a study of trace metal profiles from Jellyfish Lake, Palau, Mar. Chem., 73, 173-192.

Duce, R. A., et al. (1991), The atmospheric input of trace species to the world ocean, Global Biogeochem. Cycles, 5, 193-259.

Dutkiewicz, S., M. J. Follows, and P. Parekh (2005), Interactions of the iron and phosphorus cycles: A three-dimensional model study, Global Biogeochem. Cycles, 19, GB1021, doi:10.1029/2004GB002342.

Frew, R. D., A. R. Bowie, P. L. Croot, and S. Pickemere (2001), Macronutrient and trace-metal geochemistry of an in situ iron-induced Southern Ocean bloom, Deep Sea Res., Part II, 48, 2467-2481.

Frew, R. D., D. A. Hutchins, S. Nodder, S. Sanudo-Wilhelmy, A. TovarSanchez, K. Leblanc, C. E. Hare, and P. W. Boyd (2005), Particulate iron dynamics during FeCycle in subantarctic waters southeast of New Zealand, Global Biogeochem. Cycles, 20, GB1S93, doi:10.1029/2005GB002558.

Fung, I. Y., S. K. Meyn, I. Tegen, S. C. Doney, J. G. John, and J. K. B. Bishop (2000), Iron supply and demand in the upper ocean, Global Biogeochem. Cycles, 14, 281-296.

Galbraith, P. S., and D. E. Kelley (1996), Identifying Overturns in CTD Profiles, J. Atmos. Oceanic Technol., 13, 688-702.

Gardner, W. D., M. J. Richardson, C. A. Carlson, D. Hansell, and A. V. Mishonov (2003), Determining true particulate organic carbon: Bottles, pumps and methodologies, Deep Sea Res., Part II, 50, 655-674.

Glasby, G. P. (1971), The influence of aeolian transport on marine sedimentation in the southwest Pacific, J. R. Soc. N. Z., 1, 285-300.

Goldstone, J. V., and B. M. Voelker (2000), Chemistry of superoxide radical in seawater: CDOM associated sink of superoxide in coastal waters, Environ. Sci. Technol., 34, 1043-1048.

Häkkinen, S., and D. J. Cavalieri (1989), A study of oceanic surface heat fluxes in the Greenland, Norwegian, and Barents seas, J. Geophys. Res., 94, 6145-6157.

Heath, R. A. (1972), The Southland Current, N. Z. J. Mar. Freshwater Res., 6, 497-533.

Heath, R. (1975), Oceanic circulation and hydrology off the southern half of South Island, New Zealand, Mem. 72, 36 pp., N. Z. Oceanogr. Inst., Wellington, New Zealand.

Hudson, R. J. M., D. T. Covault, and F. M. M. Morel (1992), Investigations of iron coordination and redox reactions in seawater using $59 \mathrm{Fe}$ radiometry and ion-pair solvent extraction of amphiphilic iron complexes, Mar. Chem., 38, 209-235.

Johnson, H. L., and C. Garrett (2004), Effects of noise on Thorpe scales and run lengths, J. Phys. Oceanogr., 34, 2359-2372.

Johnson, K. S., K. H. Coale, V. A. Elrod, and N. W. Tindale (1994), Iron photochemistry in seawater from the equatorial Pacific, Mar. Chem., 46, 319-334.

Johnson, K. S., R. M. Gordon, and K. H. Coale (1997a), What controls dissolved iron concentrations in the world ocean?, Mar. Chem., 57, 137-161. 
Johnson, K. S., R. M. Gordon, and K. H. Coale (1997b), What controls dissolved iron concentrations in the world ocean? Author's closing comments, Mar. Chem., 57, 181-186.

King, D. W. (1998), Role of carbonate speciation on the oxidation rate of $\mathrm{Fe}$ (II) in aquatic systems, Environ. Sci. Technol., 32, 2997-3003.

Kuehnen, E. C., R. Alvarez, P. J. Paulson, and T. J. Murphy (1972), Production and analysis of special high purity acids purified by sub-boiling distillation, Anal. Chem., 44, 2050-2056.

Landing, W. M., C. Haraldsson, and N. Paxeus (1986), Vinyl polymer agglomerate based transition metal cation chelating ion-exchange resin containing the 8-hydroxyquinoline functional group, Anal. Chem., 58, $3031-3035$

Law, C. S., A. J. Watson, and M. I. Liddicoat (1994), Automated vacuum analysis of sulphur hexafluoride in seawater: Derivation of the atmospheric trend 1970-1993 and potential as a transient tracer, Mar. Chem., 48, 57-69.

Law, C. S., A. J. Watson, M. I. Liddicoat, and T. Stanton (1998), Sulphur hexafluoride as a tracer of biogeochemical and physical processes in an open-ocean iron fertilisation experiment, Deep Sea Res., Part II, 45 977-994.

Law, C. S., A. P. Martin, M. I. Liddicoat, A. J. Watson, K. J. Richards, and E. M. S. Woodward (2001), A Lagrangian SF6 tracer study of an anticyclonic eddy in the North Atlantic: Patch evolution, vertical mixing and nutrient supply to the mixed layer, Deep Sea Res., Part II, 48, 705-724.

Law, C. S., E. R. Abraham, A. J. Watson, and M. I. Liddicoat (2003), Vertical eddy diffusion and nutrient supply to the surface mixed layer of the Antarctic Circumpolar Current, J. Geophys. Res., 108(C8), 3272, doi:10.1029/2002JC001604.

Lewis, B. L., and W. M. Landing (1991), The biogeochemistry of manganese and iron in the Black Sea, Deep Sea Res., 38, S773-S803.

Liu, X., and F. J. Millero (2002), The solubility of iron in seawater, Mar. Chem., 77, 43-54.

Löscher, B. M., H. J. W. de Baar, J. T. M. de Jong, C. Veth, and F. Dehairs (1997), The distribution of Fe in the Antarctic Circumpolar Current, Deep Sea Res., Part II, 44, 143-187.

MacIntyre, S. (1998), Turbulent mixing and resource supply to phytoplankton, in Physical Processes in Lakes and Oceans, Coastal Estuarine Stud, vol. 54, edited by J. Imberger, pp. 539-567, AGU, Washington, D. C.

MacIntyre, S., A. L. Alldredge, and C. C. Gotschalk (1995), Accumulation of marine snow at density discontinuities in the water column, Limnol. Oceanogr., 40, 449-468

Mackie, D. S., P. W. Boyd, K. A. Hunter, and G. H. McTainsh (2005), Simulating cloud processing of iron in Australian dust: $\mathrm{pH}$ and dust concentration, Geophys. Res. Lett., 32, L06809, doi:10.1029/ 2004GL022122.

Mahowald, N., K. Kohfeld, M. Hansson, Y. Balkanski, S. P. Harrison, I. C. Prentice, M. Schulz, and H. Rodhe (1999), Dust sources and deposition during the last glacial maximum and current climate: A comparison of model results with paleodata from ice cores and marine sediments, J. Geophys. Res., 104, 15,895-15,916.

Maldonado, M. T., and N. M. Price (2000), Nitrate regulation of Fe reduction and transport by Fe-limited Thalassiosira oceanica, Limnol. Oceanogr., 45, 814-826

Maldonado, M. T., and N. M. Price (2001), Reduction and transport of organically bound iron by Thalassiosira oceanica (Bacillariophyceae), J. Phycol., 37, 298-309.

Maldonado, M. T., R. F. Strzepek, S. Sander, and P. W. Boyd (2005), Acquisition of iron bound to strong organic complexes, with different Fe binding groups and photochemical reactivities, by plankton communities in Fe-limited subantarctic waters, Global Biogeochem. Cycles, 19, GB4S23, doi:10.1029/2005GB002481.

Martin, J. H., and R. M. Gordon (1988), Northeast Pacific iron distributions in relation to phytoplankton productivity, Deep Sea Res., 35, 177-196.

McKay, R. M. L., T. A. Villareal, and J. La Roche (2000), Vertical migration by Rhizosolenia spp. (Bacillariophyceae): Implications for Fe acquisition, J. Phycol., 36, 669-674.

McKay, R. M. L., et al. (2005), Impact of phytoplankton on the biogeochemical cycling of iron in subantarctic waters southeast of New Zealand during FeCycle, Global Biogeochem. Cycles, 19, GB4S24, doi:10.1029/ 2005GB002482.

McNeil, C. L., and D. M. Farmer (1995), Observations of the influence of diurnal convection on upper ocean dissolved-gas measurements, J. Mar. Res., 53, 151-169.

Millero, F. J., and S. Sotolongo (1989), The oxidation of Fe (II) with $\mathrm{H}_{2} \mathrm{O}_{2}$ in seawater, Geochim. Cosmochim. Acta, 53, 1867-1873.

Millero, F. J., S. Sotolongo, and M. Izaguirre (1987), The oxidation kinetics of Fe (II) in seawater, Geochim. Cosmochim. Acta, 51, 793-801.
Morris, M., B. Stanton, and H. Neil (2001), Subantarctic oceanography around New Zealand: Preliminary results from an ongoing survey, N. Z. J. Mar. Freshwater Res., 35, 499-519.

Murphy, R. J., M. H. Pinkerton, K. M. Richardson, J. M. Bradford-Grieve, and P. W. Boyd (2001), Phytoplankton distributions around New Zealand derived from SeaWiFS remotely-sensed ocean colour data, N. Z. J. Mar. Freshwater Res., 35, 343-362.

Nodder, S. D., and L. C. Northcote (2001), Episodic particulate fluxes at southern temperate mid-latitudes $(42-45$ degrees $S)$ in the Subtropical Front region, east of New Zealand, Deep Sea Res., Part I, 48, 833-864.

Obata, H., H. Karatani, and E. Nakayama (1993), Automated determination of iron in seawater by chelating resin concentration and chemiluminescence detection, Anal. Chem., 65, 1524-1528.

Orsi, A. H., T. Whitworth III, and W. D. Nowlin (1995), On the meridional extent and fronts of the Antarctic Circumpolar Current, Deep Sea Res., Part I, 42, 641-673.

Powell, R. T., and A. Wilson-Finelli (2003), Photochemical degradation of organic iron complexing ligands in seawater, Aquat. Sci., 65, 367-374.

Price, J. F., R. A. Weller, and R. Pinkel (1986), Diurnal cycling: Observations and models of the upper ocean response to diurnal heating, cooling, and wind mixing, J. Geophys. Res., 91, 8411-8427.

Rue, E. L., and K. W. Bruland (1995), Complexation of iron (III) by natural organic ligands in the central North Pacific as determined by a new competitive ligand equilibration/adsorptive cathodic stripping voltammetric method, Mar. Chem., 50, 117-138.

Shaked, Y., A. B. Kustka, F. M. M. Morel, and Y. Erel (2004), Simultaneous determination of iron reduction and uptake by phytoplankton, Limnol. Oceanogr. Methods, 2, 137-145.

Shaked, Y., A. B. Kustka, and F. M. M. Morel (2005), A general kinetic model for iron acquisition by eukaryotic phytoplankton, Limnol. Oceanogr., 50, 872-882.

Stanton, B. R., and M. Y. Morris (2004), Direct velocity measurements in the Subantarctic Front and over Campbell Plateau, southeast of New Zealand, J. Geophys. Res., 109, C01028, doi:10.1029/2002JC001339.

Strzepek, R. F., M. T. Maldonado, M. T. Higgins, J. Hall, S. W. Wilhelm, K. Safi, and P. W. Boyd (2005), Spinning the "Ferrous Wheel": The importance of the microbial community in an iron budget during the FeCycle experiment, Global Biogeochem. Cycles, 19, GB4S26, doi:10.1029/2005GB002490

Sturman, A. P., P. D. Tyson, and P. C. D'Abreton (1997), A preliminary study of the transport of air from Africa and Australia to New Zealand, J. R. Soc. N. Z., 27, 485-498.

Sunda, W. G. (2001), Bioavailability and bioaccumulation of iron in the sea, in The Biogeochemistry of Iron in Seawater, edited by D. R. Turner and K. A. Hunter, pp. 41-84, John Wiley, Hoboken, N. J.

Sutton, P. (2001), Detailed structure of the Subtropical Front over Chatham Rise, east of New Zealand, J. Geophys. Res., 106, 31,045-31,056.

Thorpe, S. A. (1977), Turbulence and mixing in a Scottish Loch, Philos. Trans. R. Soc. Ser. A., 286, 125-181.

Wang, X. J., J. R. Christian, R. Murtugudde, and A. J. Busalacchi (2005), Ecosystem dynamics and export production in the central and eastern equatorial Pacific: A modeling study of impact of ENSO, Geophys. Res. Lett., 32, L02608, doi:10.1029/2004GL021538.

Wedepohl, K. H. (1995), The composition of the continental crust, Geochim. Cosmochim. Acta, 59, 1217-1232.

Weller, R., and O. Schrems (1993), $\mathrm{H}_{2} \mathrm{O}_{2}$ in the marine troposphere and seawater of the Atlantic Ocean, Geophys. Res. Lett., 20, 125-128.

Wessel, P., and W. H. F. Smith (1998), New improved version of the Generic Mapping Tools released, EOS Trans. $A G U, 79,579$.

Zafiriou, O. C., B. M. Voelker, and D. L. Sedlak (1998), Chemistry of the superoxide radical $\left(\mathrm{O}_{2}^{-}\right)$in seawater: Reactions with inorganic copper complexes, J. Phys. Chem. A, 102, 5693-5700.

E. R. Abraham, C. S. Law, and M. J. Smith, National Institute of Water and Atmosphere, P. O. Box 14-901, Greta Point, Wellington 6003, New Zealand.

P. W. Boyd, National Institute of Water and Atmosphere Centre for Chemical and Physical Oceanography, Department of Chemistry, University of Otago, Cumberland Street, Dunedin 9001, New Zealand.

P. L. Croot, IfM-Geomar, Düsternbrooker Weg 20, D-24105 Kiel, Germany. (pcroot@ifm-geomar.de)

M. J. Ellwood and S. E. Pickmere, National Institute of Water and Atmosphere, Gate 10, Silverdale Road, Hillcrest, Hamilton, New Zealand.

R. D. Frew, K. A. Hunter, and S. Sander, Department of Chemistry, University of Otago, P. O. Box 56, Dunedin, New Zealand. 